\title{
Pension schemes and labor supply in the formal and informal sector
}

\author{
Rodrigo Ceni
}

\author{
Correspondence: \\ rceni@iecon.ccee.edu.uy \\ Instituto de Economía, Facultad de \\ Ciencias Económicas y \\ Administración, Universidad de la \\ República, Montevideo, Uruguay
}

\begin{abstract}
This paper analyzes the participation path of workers in the formal and informal sectors throughout their lives and their pension eligibilities, as well as how the social security scheme can change the aforementioned participation path. High levels of informality have impacts on the benefits that workers receive, especially their pension benefits. I use Argentinean panel data from 1995 to 2008 to construct a structural discrete choice model which estimates the population's labor path and their pension eligibilities. I find evidence that low-educated workers have difficulties to obtain a pension by the age of 65 and even by age 70. Policy experiments show that if the parameters are fixed as in the pay-as-you-go (PAYG) model, there is a slight reduction in the years worked in the formal sector and the percentage of workers who obtain a Full pension. If the pension requirements (minimum age and years contributing) are stricter, there is an increase in the years spent in the formal sector but it is not sufficient to achieve the benchmark level of pension coverage. If the requirements are looser, there is a reduction in the amount of time spent in formality to contribute up to the new threshold.
\end{abstract}

Keywords: Informality, Pension, Latin America

Jel codes: $E 26, J 24, J 26,017$

\section{Introduction}

The lack of social security contributions by both the employer and the worker (commonly known as informality or informal employment) is one of the main characteristics of labor markets in developing countries. This feature not only has an impact on the current situation of those workers not receiving benefits such as health care, unemployment benefits, or extra transfers but also affects access to the pension system for the elderly. Since the work record allows agencies to properly enforce the requirements to obtain the pension mainly by checking the years spent in formality (contribution history), difficulties to meet these requirements have been noted in the academic and policy discussion (Forteza et al. 2009; Bucheli et al. 2010; Bosch and Manacorda 2012). This issue affects mainly those workers who either enter and exit the formal sector repeatedly or remain in the informal sector for many years. In the past, some workers were able to easily deceive the agencies with (false) witnesses, even if they did not meet the requirements ${ }^{1}$.

This paper discusses the impact of retirement scheme changes on individual's labor path decisions (between the informal and formal sectors) and pension eligibility. I will estimate the individuals' decision path and whether they qualify for a pension under the pension scheme which was in force in Argentina between 1993 and 2008. Then, I will

(c) The Author(s), 2017 Open Access This article is distributed under the terms of the Creative Commons Attribution 4.0 International License (http://creativecommons.org/licenses/by/4.0/), which permits unrestricted use, distribution, and reproduction in any medium, provided you give appropriate credit to the original author(s) and the source, provide a link to the Creative Commons license, and indicate if changes were made. 
explore changes to the main variables of that scheme. In particular, I will explore changes in (i) the number of years contributing to the system and (ii) the minimum age. Both are requirements to obtain a pension. Furthermore, this paper deals with the reform of the pension system from a mixed system where two pillars coexist (a pay-as-you-go (PAYG) system and an individual capitalization system) to a new system with only one of those pillars. In order to summarize the different systems, I consider the replacement rate as the main characteristic of each scheme and the different types of pensions Full, Advanced age, or Survivor.

In Latin America, about 50\% of salaried workers are employed informally, where informal workers are defined as those who are not covered by labor regulations, such as taxes, a right to the health system, and a right to receive a pension income at retirement age (Portes et al. 1989; Perry et al. 2007; Schneider 2012). This feature poses at least two major challenges to governments. First, governments are faced with the problem of meeting their current pension budget due to the lack of social contributions that are needed to provide social protection in old age. The second challenge is to deal with the fact that governments need to give the right incentives for future pensioners to meet the requirements. In order to understand how pension characteristics can shape an individual's incentive to decide between the formal and informal sector, it is necessary to understand the nature of informality.

There are three strands in the literature on informal work. The first idea holds that formal and informal markets have different rules which are respectively associated with a high and a low productivity sector, that the formal/informal decision is basically not up to workers, and that they work informally because they cannot get a formal job (La-Porta and Shleifer 2014). This concept has been discussed by a second strand of the literature which proposes a single market with workers deciding where to work based on their own characteristics, wages, and benefits. This strand is based on empirical literature such as Magnac (1991); Maloney (2004); Pratap and Quintin (2006), and Bucheli and Ceni (2010). The third strand is given the name of moderate dualism. The present paper follows this strand (as in Perry et al. 2007; Galiani and Weinschelbaum 2007; Amaral and Quntin 2006; Ceni 2013) to capture some ideas from both segmented markets and from a single market through heterogeneous individuals, some of whom can choose while others cannot. This paper firstly contributes to modeling the moderate dualism of informality through a partial equilibrium model in which workers decide to work either formally or informally. In single markets, depending on their education level and experience, workers have different wage functions and face differential market imperfections, such as different entry costs, probability of losing their job, and home production productivity. It follows that wages and market imperfections play a role in segmenting the market.

This paper contributes to and is related to the literature about incentives in formal labor supply. The choice to work in the formal or in the informal sector is based on the cost and benefits of working formally (Holzmann et al. 2009; World Bank 2010; Bergolo and Cruces 2014). These papers focus on the specific effect of some social transfers (such as noncontributory pensions) in the considerable mobility between formality and informality and in how much to work in the formal sector and find that poor individuals choose to work informally in order not to lose some benefits. In this paper, a higher pension in old age acts as an incentive to spend more time in formal employment. 
In the tradition of discrete choice models (Keane and Wolpin 1997), I develop a dynamic behavioral model which captures the individual decision to work either in the formal or the informal sector under the characteristics of the pension scheme. The individual has to decide whether to work in the formal or informal sector or remain unemployed. This decision depends on the current wage applicable in each sector, the earning paths, and the main institutional characteristics of the pension scheme. Labor supply behavior in the context of informality has been analyzed in some recent papers for the Chilean case (Todd and Velez-Grajales 2008; Attanasio et al. 2011; Otero 2013; Joubert 2015). These papers assess the behavior of individuals or households among the covered and uncovered sectors ${ }^{2}$, when changing the rules of the pension system or shaping a pension design. Another contribution of this paper is the kind of dataset used in the analysis: instead of using administrative records, I use survey data. This allows me to work with a direct definition of informality and for the specific case of Argentina where informality is a critical problem. The definition that I use is directly related to the pension benefit, which I prefer because in developing countries, having a contract does not directly mean having a wide range of benefits. Besides, Argentina presents higher levels of informality than Chile, which is one of the main obstacles the model can deal with. Finally, I will only consider salaried male workers to avoid fertility-related decisions in the model.

This paper also contributes to the analysis of the retirement decision and to estimating the pension coverage rates. The decision to retire takes into account the rewards (pecuniary) and benefits (non-pecuniary) of being a pensioner and of being a worker. Individuals know they have a finite lifespan, but if they continue working, they will receive a higher pension amount. French and Jones (2011) estimate a retirement dynamic model which includes the decision of how much to save and how much to devote to medical expenses, with special attention paid to the different systems of medical expenses and the role of health insurance. The paper points out the relevance of Medicare (in the USA) eligibility in labor decisions for individuals over 60 years old. In my estimation, most of the individuals decide to retire as soon as possible and there are no incentives in the benchmark to continue working. To estimate pension coverage, Bucheli et al. (2010) and Berstein et al. (2006) simulate work trajectories by using reduced form estimation methods. These papers estimate, for Uruguay and Chile respectively, a gap in coverage among females and the self-employed, especially. Forteza et al. (2009) show that in the pre-2008 pension scheme in Argentina, only 40\% of men would reach at least 30 years of contributions. Bosch and Guajardo (2012) show that the share of individuals aged 65+ with a pension income decreases between 1992 and 2007 from about 85 to 65\% among men (mainly due to self-employment). In this paper, I estimate the pension coverage for those individuals at age 65 and 70 and find that the majority of those who have completed primary school cannot obtain a Full pension. Among those who can, half continue working after the age of 65.

Finally, this paper contributes to assessing how changes in pension schemes affect individual behavior. Governments determine pension schemes, which are defined by the minimum requirements to obtain a pension: the number of years contributing to the system, the minimum age, and the replacement rates. These three elements in the model determine the minimum length of working life and the condition to qualify for higher pension benefits when an individual reaches pensionable age. Lower replacement rates and 
loose rules reduce formality, and stricter rules increase it. Changes mainly occur in the last 10 years of an individual's working life, when they are closer to reaching the minimum thresholds.

\section{Informality in Argentina}

Informality is present in all countries in Latin America to varying degrees depending on the level of development and the institutional framework. These differences are due to the general level of development of the countries and the institutional framework, such as the quality of the benefits or the level of government enforcement. Argentina is in a midrange position for Latin America with more than 35\% of salaried workers in informality, with a higher level among females and those with less education; meanwhile, the most advanced countries (Chile and Uruguay) have about $20 \%$ and the least advanced ones more than half (Appendix: Tables 9 and 10).

I perform a multinomial logit with Argentinean data from the $1995-2008$ period ${ }^{3}$ to study the incidence of the informality in that period and the transitions between states ${ }^{4}$. I consider only salaried workers so as not to include fertility decisions, and self-employed individuals are not included because there is no data about their contributions. Based on this model, Table 1 shows marginal effects estimated from the model, so age, education, and years of experience have a positive effect on formality (and a negative effect on informality). Being married and the head of the household has a positive effect on working formally and a negative effect on working informally, and meanwhile, being single has a negative effect in both sectors.

Then, using this model, I predict the probability of being in each sector using some observable variables. Firstly, the distribution by education shows that formality increases and informality and unemployment decrease with educational attainment, as shown in Table 2 . The probability of being unemployed in the lower level of educational attainment

Table 1 Marginal effects based on the multinomial model (men only)

\begin{tabular}{llll}
\hline Marginal effects 1995-2008 & & & \\
& Unemployed & Formal & Informal \\
\hline Unemployed $(-1)$ & $0.0748^{* * *}$ & $0.0466^{* * *}$ & $-0.1215^{* * *}$ \\
& $(0.0015)$ & $(0.0032)$ & $(0.003)$ \\
Formal $(-1)$ & $-0.0184^{* * *}$ & $0.3322^{* * *}$ & $-0.3138^{* * *}$ \\
& $(0.0014)$ & $(0.0010)$ & $(0.0014)$ \\
Age & $0.0012^{* * *}$ & $0.0004^{* * *}$ & $-0.0016^{* * *}$ \\
& $(0.0001)$ & $(0.0001)$ & $(0.0001)$ \\
Education & $-0.0036^{* * *}$ & $0.0706^{* * *}$ & $-0.067^{* * *}$ \\
& $(0.0011)$ & $(0.0015)$ & $(0.0017)$ \\
Married & $-0.0095^{* * *}$ & $0.0273^{* * *}$ & $-0.0178^{* * *}$ \\
& $(0.0035)$ & $(0.0045)$ & $(0.0049)$ \\
Single & $0.022^{* * *}$ & $-0.0153^{* * *}$ & -0.0068 \\
& $(0.0037)$ & $(0.0049)$ & $(0.0056)$ \\
Head & $-0.0213^{* * *}$ & $0.043^{* * *}$ & $-0.0217^{* * *}$ \\
& $(0.0020)$ & $(0.0025)$ & $(0.0028)$ \\
Tenure & $-0.0350^{* * *}$ & $0.0539^{* * *}$ & $-0.0189^{* * *}$ \\
& $(0.0005)$ & $(0.0008)$ & $(0.0008)$ \\
\hline
\end{tabular}

Standard errors in parentheses

${ }^{*} p<0.10,{ }^{* *} p<0.05,{ }^{* * *} p<0.01$ 
Table 2 Distribution in each sector by education, age group, and marital status based on the multinomial model (men only)

\begin{tabular}{llll}
\hline Distribution in each sector 1995-2008 & & & \\
\hline Education & Unemployed & Formal & Informal \\
Low education & 0.1137 & 0.4796 & 0.4067 \\
Medium education & 0.0861 & 0.6594 & 0.2545 \\
High education & 0.0423 & 0.8578 & 0.0999 \\
Age group & Unemployed & Formal & Informal \\
23-28 & 0.1143 & 0.5157 & 0.3700 \\
$29-34$ & 0.0767 & 0.6350 & 0.2883 \\
$35-44$ & 0.0640 & 0.7048 & 0.2312 \\
$45-54$ & 0.0652 & 0.7254 & 0.2094 \\
$55-65$ & 0.0829 & 0.7091 & 0.2080 \\
Total & 0.0894 & 0.6211 & 0.2895 \\
\hline
\end{tabular}

(incomplete high school or less) is twice as much as in the highest one (college complete) ${ }^{5}$. Comparing the highest education level with the lowest one, the probability of being in the formal sector is two times higher and the probability of being informal is four times lower. The change in probabilities when workers achieve a college degree is remarkable ${ }^{6}$. The probability of being unemployed decreases by more than 4 points, the probability of being in the formal sector increases by almost 20 points and the probability of being informal decreases by more than 15 points.

The data by age groups shows that the probabilities for the unemployed decrease until the 50s and then increase, while formality has the opposite behavior, increasing and then slightly decreasing. Meanwhile, informality decreases with age but the percentage remains stable after the age of 45 . Being in the formal sector is 20 points more probable for those over the age of 35 than workers in their 20s, and being in the informal sector is 15 points less probable. In general, the characteristics of formality, informality, and unemployment are in line with the literature (Loayza et al. 2009; Hazans 2011).

Additionally, to analyze the mobility of workers among states, I assess the marginal effect and the predictions of the model. Firstly, Table 1 shows that being in the formal sector in the previous period has a relevant effect on remaining in formality in the current period, which it is easier to enter formality from unemployment than from informality and it is easier to lose an informal job than a formal one. Secondly, Table 3 shows the predicted probability of transitions of active salaried workers. In the first block, the elements of the principal diagonal represent the shares of individuals who do not switch in each year ${ }^{7}$. The rows in the table are the original sector where the workers were in the previous year $(t-1)$, and the columns are the current sector $(t)$. It is important to note that formality is 20 points more stable than informality, and about $38 \%$ of the unemployed remain in this situation for two consecutive years. At the same time, the informal sector appears more unstable than the formal sector, but it is easier to enter into from unemployment ( $40 \%$ instead of $23 \%$ ), a feature which gives some attractiveness to this sector. Additionally, $20 \%$ of informal workers move into the formal sector each year after, for example, gaining some experience or unemployment.

These changes can also be analyzed by education level. In the second block, we can observe the transition from unemployment. The percentage who remain in unemployment is declining in education levels (40,37, and $34 \%$ respectively); for those who change 
Table 3 Probabilities of being in each sector, based on the multinomial model 1995-2008 (men only)

\begin{tabular}{llll}
\hline Probability of being in each sector & & & \\
& Unemployed & Formal & Informal \\
Unemployed $(-1)$ & 0.3797 & 0.2270 & 0.3934 \\
Formal $(-1)$ & 0.0282 & 0.8916 & 0.0802 \\
Informal $(-1)$ & 0.1123 & 0.2140 & 0.6737 \\
Probability of being unemployed by education and sector in previous period & \\
Education & Unemployed $(-1)$ & Formal $(-1)$ & Informal (-1) \\
Low education & 0.3947 & 0.0417 & 0.1121 \\
Medium education & 0.3697 & 0.0266 & 0.1118 \\
High education & 0.3429 & 0.0141 & 0.1154 \\
Probability of being formal by education and sector in previous period & \\
Education & Unemployed $(-1)$ & Formal $(-1)$ & Informal (-1) \\
Low education & 0.1758 & 0.8362 & 0.1704 \\
Medium education & 0.2531 & 0.8984 & 0.2528 \\
High education & 0.3834 & 0.9492 & 0.3920 \\
Probability of being informal by education and sector in previous period & \\
Education & Unemployed $(-1)$ & Formal $(-1)$ & Informal $(-1)$ \\
Low education & 0.4295 & 0.1221 & 0.7175 \\
Medium education & 0.3771 & 0.0751 & 0.6354 \\
High education & 0.2737 & 0.0367 & 0.4926 \\
\hline
\end{tabular}

to formal employment, the percentages are quite low, but still, the probability of losing their formal jobs is almost three times lower for better educated workers (4.2, 2.6, and $1.4 \%$ from low to high education level). In the case of informal workers, this probability is about $11 \%$ and there are no differences among education levels.

The third block of Table 3 shows the transitions to formality. It is shown that formality is remarkably more stable among the better educated individuals (10 points higher), and educated workers who were in the informal sector are much more likely to change to the formal sector than low-educated workers (22 points more). Among unemployed workers, the percentages entering the formal sector are $17.6 \%$ for the low-educated, $25.3 \%$ for workers with medium levels of education, and 38.3\% for those with higher levels. Formality has fewer barriers to entry for highly educated workers than for the others. Conversely, informality is more stable among low-educated workers, and it is their means of exit from unemployment (block four in Table 3).

Trajectories are clearly determined by education and the gate of entrance. Those workers who start to work in the formal sector at an early age generally remain there for their whole working life, and this is more likely for highly educated workers. Conversely, those workers who originally enter the labor market in an informal position tend progressively to move to formality as a function of both age and experience; these trajectories are more probable for low-educated workers. Then, there are workers who move between sectors, having interruptions in their contributions history. Those following these two latter trajectories will have more difficulties meeting requirements for a pension.

\section{The Argentinean background: pension system and savings}

Several reforms in pension schemes have been implemented since the beginning of the 1980s in many developing countries ${ }^{8}$. These reforms have aimed to cover the increasing 
public budget deficit associated with the demographic transition ${ }^{9}$ and the political use of pension schemes. The former system allowed politicians to obtain electoral support in a way that had an exaggerated and undesirable effect because the worker only needed some witnesses to confirm their work history. These reforms also entail the substitution of the witnesses for administrative work records to confirm fulfillment of the requirement.

Argentina is a special and interesting case because, on the one hand, it is in an advanced stage of demographic transition, reaching the same levels as developed countries ${ }^{10}$ and, on the other hand, the system has been subject to a number of reforms in the last 20 years. The first reform, established in 1993, transformed a public PAYG with persistent and increasing deficits into a mixed system (PAYG and individual capitalization) in which private and public institutions coexist. The reform was triggered by the need to make the system sustainable. The first pillar was a PAYG scheme, which was financed by employers' contributions (16\% of gross taxable income), and the workers would obtain a universal pension benefit with 30 years of contribution and at 60 or 65 years old for women and men respectively. The pension payment was a monthly flat amount of about $28 \%$ of the average wage. The second pillar was financed by employees' contributions (11\% of gross taxable income), which financed the PAYG or individual capitalization scheme (Rofman 2000). This reform and its consequences were studied in depth by academics, and it was discussed during the last decade at the political level.

The Argentinean program severely punishes short contribution careers relative to other countries in the region (Forteza and Ourens 2009). Conversely, the program also widely promotes additional programs to allow access to special pensions for those whose years of contributions are insufficient to be eligible for either the Full (30 years minimum required) or the Advanced age (10 years minimum required) pensions. Additionally, there has also been an increase in the level of the minimum pension in the last few years (Rofman et al. 2010). These changes have led to the idea that the pension system is an essential factor in changes to individual career paths with respect to formal/informal employment), because workers can believe that even if they are informal, the government's commitment to maintaining some requirement to access a pension will be relaxed (Forteza et al. 2009). Moreover, if the requirements to access a pension are too strict and only a small share of the population can enjoy it, the government will be forced either to change the rules or to create new types of non-contributory pensions.

In particular, a Moratorium was introduced in 2007 as part of the Pension Inclusion Program $^{11}$ to include mainly women and self-employed workers who have eligibility difficulties in the pension system. Assessments of the Moratorium (e.g., Bosch and Guajardo 2012; Bosch and Manacorda 2012) determined that is has an effect, increasing the informality among workers close to retirement age. But, these studies cannot provide answers about either the effect among the self-employed because this was not measured in the household survey or the effect among women because their situation has many ingredients such as fertility and home production which are not included here.

Finally, in December 2008, as a consequence of the global financial crisis which started in September 2008 and after more than a decade of criticism of the multi-pillar regime, the scheme changed again, returning to a single public pillar with a PAYG scheme. The pension is composed of the universal pension benefit and compensatory pension, which is included to compensate for the elimination of individual capitalization. This system is financed by current contributions, and shortfalls in the current period are covered by 
general taxation or deficits. The employee and employer contributions have not changed, but the administrator of the resources has changed. Despite this reform, the requirements to access a pension are still relatively strict in comparison with the rest of the region. In the model estimation, I will consider the 1995-2008 period in order to capture the first scheme.

The severe financial crisis that Argentina suffered in 2001 deeply affected savings decisions, because many banks closed and savers lost a lot of their money. Moreover, in the last 2 years, many restrictions have been imposed to prevent private access to foreign currency which has traditionally been the main way for families to save. In this paper, however, the pension system is analyzed in relation to implicit savings decisions of the elderly. I have decided not to take into account savings decisions in the model. I also regard the rate of replacement as a moment (statistics) that summarizes the different schemes because the multi-pillar scheme was only active for 14 years and, therefore, there was no possibility to observe an entire generation in the system during its whole working life.

\section{Model}

The model describes the decision problem of individuals in the subsequent periods after they leave the education system until they $\mathrm{die}^{12}$. In each period, individuals choose between working in the formal or informal sector and being unemployed. Individuals have an endowment of human capital which was acquired in the past and depends on the years of schooling and also on the experience they have acquired by working in formal and informal jobs. This latter point means that employers in the model cannot distinguish the sector where the experience of workers has been gained. For instance, I assume that a young individual at 23 leaves the education system with a level of formal education between incomplete elementary school and a university degree. They face a finite horizon decision and choose among the different options that they have as in the seminal paper of (Keane and Wolpin 1997).

This model is a partial equilibrium where the employment status and wages are determined considering only the supply side of the equilibrium. As was mentioned before, this model exploits the way workers' decisions during their active working life are shaped by current and future rewards, and there are no features that come from the demand side. Including these features would introduce complexity to the model, and the question that I want to respond to can be answered without them. Firms are not modeled as having an explicit role, but there is a group of ingredients which incorporates the barriers and difficulties that workers have to deal with, such as probability of losing their job $\left(\lambda_{j}(S)\right)$, probability of finding a job $\left(\phi^{j}(S)\right.$ ), and the costs of obtaining formal employment $\left(\mathbb{C}^{F k}\right)$.

All individuals receive some rewards in each state, even if they do not work. I consider not only the benefits that formal workers enjoy $\left(B_{1}\right)$ and rewards the time spent on home production and leisure during their active working life $\left(B_{2}\right)$ but also the leisure for pensioners $\left(B_{3}\right)$. These two latter functions represent options outside of explicitly pecuniary rewards.

The individuals' choices are based on a state space with six dimensions, that is the time which defines the stage of the worker's life $(a)$, the education level which introduces initial heterogeneity to the individuals $(S)$, the experience in the labor market which is gained if the individuals work either formally or informally $(X)$, the number of years of formal 
employment which has been accumulated from experience in the formal sector $\left(a_{F}\right)$, the sector the individual was active in the previous period $\left(\mathbf{I}_{k}^{t-1}\right)$, and a random shock to formal and informal wages $\left(\epsilon(a)^{j}\right)$.

The rewards for those who are working are comprised of the wage they earn and a benefit function. In each period, the individual can earn from among a set wages possible in each sector which is determined by two Mincer equations. The wages depend on the education level and the experience gained from work (both formal and informal). Formal workers receive also a set of benefits $\left(B_{1}\right)$ which varies by education level, as a result of, for example, bargaining power.

Receiving unemployment compensation depends on whether the worker qualifies for unemployment insurance. If the worker works formally, the worker may receive the insurance in $t+1$, at a fixed percentage $\left(b_{2}\right)$ of the previous wage, in addition to the benefit $B_{2}(X, S)$ which reflects presumed leisure or home production. The functional form of the home production-leisure function increases with education and decreases with experience in the job market.

The working life is classified into three stages. The first one is the pure active life, where the worker can either work in the formal or informal sector or be unemployed. The second stage is the elective retirement stage where those workers who are eligible for retirement can choose to retire or continue working and those who are not eligible continue as in the pure active life stage. The third and last stage is the compulsory retirement stage where everyone is in retirement even if they are not eligible for a pension. In this last stage, everyone receives a pension. These stages are introduced in the model through three value functions (see the "Mathematical model" section in the Appendix).

The first stage of analysis is the pure active life until age $A_{1}$, when individuals decide whether to retire early or continue working, taking into account not only the current and the future value function but also the transition probabilities. On the one hand, the job loss probabilities, which are the probabilities of formal and informal job destruction, are captured by the term $\lambda_{j}(S)$, and on the other hand, the probability of finding a job either in the formal or the informal sector by $\phi^{j}(S)$ both defined for different education levels. Therefore, the value function of working in formality $V^{F}$ (informally $V^{I}$ ) is defined with the formal (informal) reward function $\left(R_{j}\right)$, the costs of obtaining formal employment which depends on the educational attainment, the age and the sector of the worker in the previous period $\left(\mathbb{C}^{F k}\right)$, and the expected value of labor income flows from all the years in the first stage (pure active working life) plus the value function of the second and the third stages. The value function for unemployed workers depends on the current utility function, which differs depending on whether the workers were formal or informal in the previous period, and the expected utility function.

The second stage of analysis is between the minimum age to obtain a pension $\left(A_{1}\right)$ and the age $\left(A_{2}\right)$ at which pension is compulsory and everyone is retired. In this stage, individuals can also choose to continue to work in either formal or informal sectors or be unemployed, but those individuals who satisfy the minimum years in the formal sector $\left(F_{1}\right)$ may obtain a Full pension (FP), so they could be retired and also enjoy the pensioner's home production-leisure benefit $\left(B_{3}\right)$. The individual may opt to (retire and) receive a pension at any point during this stage if the total years worked in the formal sector $\left(a_{F}\right)$ reaches at least the minimum threshold $\left(F_{1}\right)$. Note that being retired is always a choice in this stage of the workers' life and there are three levels of FPs which depend on $a_{F}$. If 
workers decide to continue working, they can achieve a higher replacement rate in the future, but this decision has drawbacks because their life is limited to the age $\bar{A}$ at which everyone in the model dies.

The third stage of analysis starts at $A_{2}$ years old when all the individuals are retired. The value function of these pensioners is determined by the income that the individual would receive and the number of years in formal employment $\left(F_{1}\right.$ and $\left.F_{2}\right)$. It is determined by the replacement rate and the last wage received in their active working life. There would be three types of pensions: Full, Advanced age pension (AP), and Survivor pension (SP). At the age of $A$, everyone is dead. The replacement rate $\left(r_{F}\right)$ in the FP type is not uniform; it increases with the number of years that the workers are in the formal sector.

\section{Estimation}

The estimation has three components: first, I estimate some parameters outside of the model using the data from the $\mathrm{EPH}^{13}$, and then, a second group of parameters related to the functional forms and idiosyncratic shocks are estimated through the model using the simulated method of moments (SMM), and finally, I calibrate a third group of parameters with the data. The estimation uses data for the 1995-2008 period, where the pension scheme did not experience any change, and in the reduced form estimations, there are year effects to capture the cyclical component and to have average parameters for the period.

In Table 4, I show the estimation of the Mincer equation for formal and informal workers. Each worker, based on their educational endowment and the experience that they obtain in the labor market, receives a wage offer which forms part of their utility function and decides either to work or to remain unemployed. Both education and experience are better rewarded in the case of formal workers, but bigger differences are noted in how the experience is rewarded in the formal sector ${ }^{14}$. However, informal workers receive better offers in their youth, as reflected by a higher constant term. The transition function $\left(\lambda_{j}\right.$ and $\phi_{j}$ ) parameters (education endowment and years of experience) are estimated as a marginal effect in the multinomial function shown in Table 1.

The SMM estimation is done by maximizing the conditional value function on the state variables, minimizing the distance between the estimated moments in the model and the moments in the data, and then weighing with the inverse of the estimated variance of the moments. I select as moments the share of formality, informality, and unemployment by age groups and the educational endowment, and the transition rates between formality, informality, and unemployment, to estimate the discount factor $\beta$, the shape of the

Table 4 Parameters of the Mincer equation

\begin{tabular}{llll}
\hline $\begin{array}{l}\text { Coefficients estimated from the Mincer equations } \\
\text { Name }\end{array}$ & Symbol & Value & Standard deviation \\
\hline Constant formal & $\alpha_{0}^{f}$ & 0.2606 & $(0.0227)$ \\
Constant informal & $\alpha_{0}^{i}$ & 0.3962 & $(0.0805)$ \\
Schooling formal & $\alpha_{1}^{f}$ & 0.2982 & $(0.0027)$ \\
Schooling informal & $\alpha_{1}^{i}$ & 0.2707 & $(0.0056)$ \\
Experience formal & $\alpha_{2}^{f}$ & 0.1622 & $(0.0035)$ \\
Experience informal $_{\text {Experience }}^{2}$ formal & $\alpha_{2}^{i}$ & 0.0979 & $(0.0057)$ \\
Experience $^{2}$ informal & $\alpha_{3}^{f}$ & -0.0117 & $(0.0004)$ \\
\hline
\end{tabular}


utility function $\gamma$, the parameters that determine the home production-leisure function, the parameters to shift to formality from informality or unemployment, and the standard deviation of the idiosyncratic shocks presented in Table $5^{15}$.

The parameters estimated by SMM are shown in Table 5. The first block shows the general parameters of the model, namely the estimation of the discount factor and the risk aversion ( 0.95 and 1.28 respectively) which are a bit lower than in the literature ${ }^{16}$. The second block shows the parameters of the benefits additional to wages that the formal workers enjoy, which is fixed at zero for those in the lower education level. In the third block, there are the home production-leisure parameters in active working life and, in the fourth block, the parameters in retirement. The parameters of home production and leisure trade-offs imply higher opportunity costs for the better educated. In the fifth block, there are the parameters of the monetary and time costs of obtaining formal employment: the lower-educated face higher costs than the highly educated individuals.

Finally, some parameters are calibrated as shown in Table 6 . The minimum retirement age $\left(A_{1}\right)$ of 65 years old is the minimum age to obtain the FP, and 70 years old $\left(A_{2}\right)$ is the age to obtain the AP. Additionally, to obtain the FP, workers must work at least 30 years

Table 5 Parameters estimated by simulated method of moments (SMM)

\begin{tabular}{|c|c|c|c|}
\hline \multicolumn{4}{|c|}{ Parameters estimated by simulated method of moments } \\
\hline Name & Symbol & Value & Standard deviation \\
\hline Discount factor & $\beta$ & 0.9475 & $(0.0014)$ \\
\hline Risk aversion & $\gamma$ & 1.2757 & $(0.0018)$ \\
\hline \multicolumn{4}{|l|}{ Benefits $B_{1}(S)$} \\
\hline Medium education & $B_{1}(2)$ & 0.4691 & $(0.0004)$ \\
\hline High education & $B_{1}(3)$ & 0.9382 & $(0.0002)$ \\
\hline \multicolumn{4}{|l|}{ Home production in active life $B_{2}(X X, S)$} \\
\hline Constant & $b_{22}$ & 100.9925 & $(5.589)$ \\
\hline Low education & $b_{21}(1)$ & 38.1481 & $(0.781)$ \\
\hline Medium education & $b_{21}(2)$ & 36.9016 & $(1.631)$ \\
\hline High education & $b_{21}(3)$ & 49.5058 & $(2.396)$ \\
\hline Low education & $b_{23}(1)$ & 43.465 & $(1.090)$ \\
\hline Medium education & $b_{23}(2)$ & 51.5392 & $(0.925)$ \\
\hline High education & $b_{23}(3)$ & 57.3335 & $(2.557)$ \\
\hline \multicolumn{4}{|l|}{ Home production in retirement life $B_{3}(S)$} \\
\hline SP & $b_{3}$ & 1838.1 & $(2.0)$ \\
\hline Low education & $b_{31}(1)$ & 1060.395 & $(1.87)$ \\
\hline Medium education & $b_{31}(2)$ & 3182.1625 & $(48.91)$ \\
\hline High education & $b_{31}(3)$ & 2113.5710 & $(112.4)$ \\
\hline \multicolumn{4}{|l|}{ Cost of entering in formality } \\
\hline Age multiplier & $\Pi$ & 97.6199 & $(4.09)$ \\
\hline Informal-formal (low education) & $\phi_{11}(1)$ & 1.18 & $(0.0141)$ \\
\hline Informal-formal (medium education) & $\phi_{11}(2)$ & 0.591 & $(0.0)$ \\
\hline Informal-formal (high education) & $\phi_{11}(3)$ & 0.0004 & $(0.0)$ \\
\hline Unemployed-formal (low education) & $\phi_{12}(1)$ & 45.044 & $(1.22)$ \\
\hline Unemployed-formal (medium education) & $\phi_{12}(2)$ & 4.504 & $(0.12)$ \\
\hline Unemployed-formal (high education) & $\phi_{12}(3)$ & 0.015 & $(0.0)$ \\
\hline \multicolumn{4}{|l|}{ Shocks } \\
\hline Std. deviation informal & $\sigma^{i}$ & 0.3602 & $(0.00)$ \\
\hline Std. deviation formal & $\sigma^{f}$ & 0.2109 & $(0.00)$ \\
\hline
\end{tabular}


Table 6 Parameters calibrated

\begin{tabular}{lll}
\hline Parameters calibrated & & Symbol \\
Name & & Value \\
\hline Thresholds & $A_{1}$ & 65 \\
Minimum full retirement age & $A_{2}$ & 70 \\
Advanced age retirement age & $\bar{A}$ & 80 \\
Death & $F_{1}$ & 30 \\
Years of formal work to obtain FP & $F_{2}$ & 10 \\
Years of formal work to achieve AP & & 1.13 \\
Replacement rates & $r_{F-40}$ \\
FP 3 (40 years of formal work) & $r_{F-35}$ & 0.96 \\
FP 2 (35 years of formal work) & $r_{F-30}$ & 0.81 \\
FP 1 (30 years of formal work) & $r_{A}$ & $0.7^{*} r_{F-30}$ \\
AP & $b_{2}$ & 0.6 \\
Unemployment benefits for former formal workers & &
\end{tabular}

Source: (Forteza and Ourens 2009) and (Rofman et al. 2010)

in the formal sector $\left(F_{1}\right)$ and at least 10 years $\left(F_{2}\right)$ to get the AP. The FP has three levels with three different replacement rates at $30\left(r_{F-30}\right), 35\left(r_{F-35}\right)$, and $40\left(r_{F-40}\right)$ years in formality with $0.81,0.96$, and 1.13 being the respective replacement rates. The AP is at $70 \%$ of the FP with 30 years of formality. Everyone in the model dies at the age of $81(\bar{A})$.

In Table 7, the moment matching of the formal and informal activity by education is shown. The model matches quite well taking into consideration the interval, especially among the highly educated and in the general estimation, although there are some issues with the model specification at the beginning (underestimating formality) and the end of the career (overestimating formality). In the case of workers with low and medium levels of education, there is an underestimation (more than 10 points) at the beginning and an overestimation (also 10 points) in the last years of the career. In the case of the informal sector, the model behavior is again quite good in the general case and in the estimation related to workers with medium levels of education, but it underestimates formality in the low-educated group ${ }^{17}$.

The model behavior is also quite good at fitting the transitions among sectors ${ }^{18}$, because formal workers tend to stay in a similar situation for longer than informal workers or the unemployed. It is easier for the unemployed to enter the informal sector than the formal one. However, the transition from unemployment to informality is underestimated.

Using this parameterization, I estimate the pension eligibilities for the different education levels at 65 and 70 years old as shown in the first panel of Fig. 1. All the workers are eligible for at least an AP, since the requirements are very loose: only 10 years of contribution or formality. As regards the low-educated workers, almost $54 \%$ obtain the AP and $44 \%$ the first level of FP (21.5\% at 65 and $22.9 \%$ at 70 years old). Note that most of these individuals obtain the pension after the age of 65 , so they continue working in order to obtain this benefit ${ }^{19}$. A small share of workers with medium levels of education continue to work after 65 in order to obtain a FP, and less than $1 \%$ get only the AP. By the age of $70,58 \%$ of these workers reach the first level of FP, $41 \%$ the second level, and less than $1 \%$ the third one. Most highly educated workers obtain the second and third levels of the FP. In this estimation, the main problem with pension eligibility is in the lower part of the 


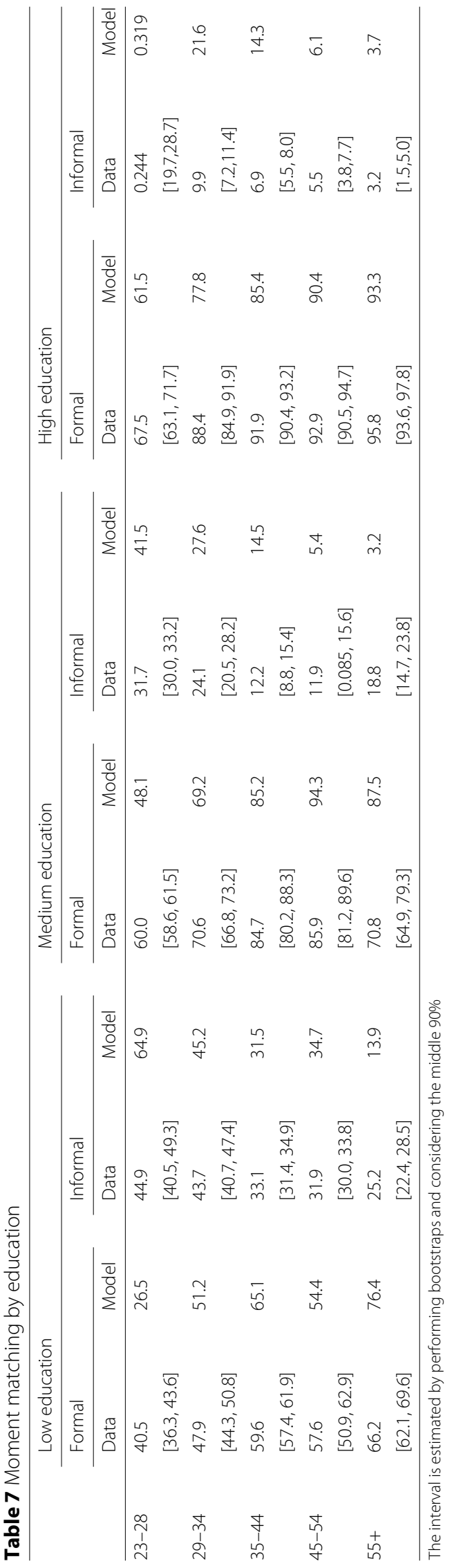




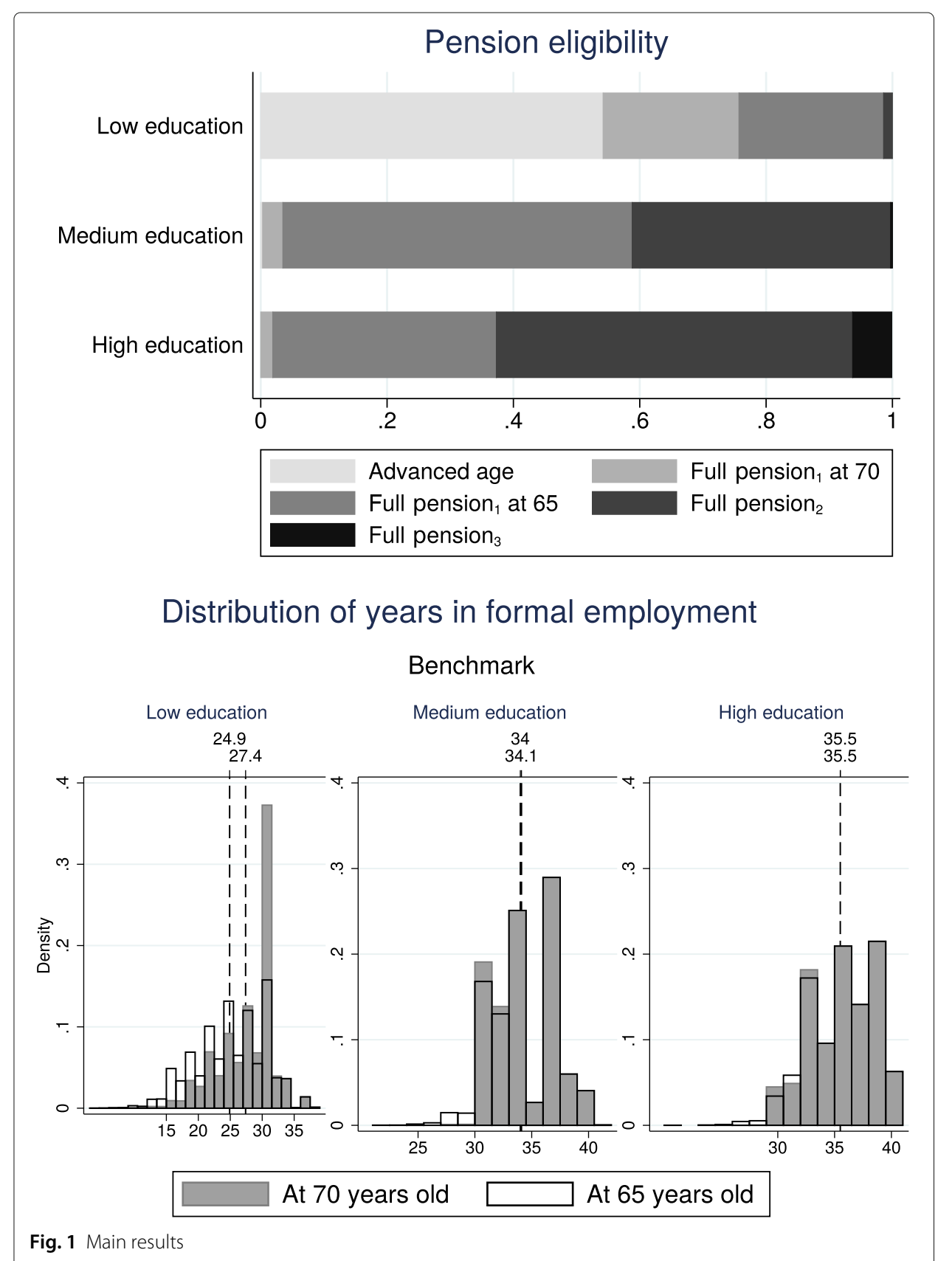

distribution, which is almost the half of the total population. Most highly educated workers obtain a pension, while the low-educated ones in many cases have to work until the age of 70 just to qualify for an AP. This point will be discussed in the policy experiments.

Additionally, the second panel of Fig. 1 shows the distribution of the formality path. Regarding workers with high and medium education levels, the distribution is similar at 65 and 70 years old; a small share continue in active working life until they reach the first level of a FP with 30 years of formality. Most low-educated workers continue their active working life after 65 , although few of them reach the minimum requirements. Between the ages of 65 and 70, low-educated workers work an average of 2.5 additional years in 
formality. Note that most workers prefer to retire when they have the possibility, so the main difference in distributions is due to the impossibility of getting a pension and not the question of qualifying for a higher pension.

\section{Discussion: policy experiments}

In this section, I want to perform some policy experiments in order to discuss different situations and their consequences in terms of pension eligibility. I select these policies because they are usually among options discussed by policymakers and different interest groups. First, I will analyze the effect of a lower replacement rate (as in a PAYG scheme) ${ }^{20}$ and a lower age of retirement ( 60 instead of 65 years old). In the second policy, I make the requirements stricter, increasing the number of years of formality to qualify for a FP. In the third policy, formality requirements are looser, and in the fourth, I raise the minimum age to retire by 2 years. Finally, I estimate welfare consequences of all these policies.

The first policy experiment is to drastically reduce the replacement rate that the workers would get with one of the $\mathrm{FPs}^{21}$ and set the minimum age to get a pension at 60 (instead of 65). Individuals can obtain a pension 5 years earlier, but at a lower monetary reward. Formality decreases towards the end of careers. For low-educated workers, the fall is almost 20 points, and for those with medium and high levels of education, the fall is 10 and 15 points respectively. Those workers decide to be unemployed rather than work ${ }^{22}$.

The pension eligibility changes are shown in the first panel of Fig. 2 . The main change for those with high and medium levels of education is the rise in the number who reach the first level of the FP and a decrease in the number reaching the second level, 60 and 40 points respectively. The percentage of workers with low education levels who obtain a FP is 13 points lower than in the benchmark, with a corresponding increase in the share covered by the AP. This trend is confirmed in the second panel of Fig. 2, which shows the distribution of years in formal employment. Workers with high and medium education levels work in the formal sector as in the benchmark until they reach the requirements for a FP, after which point they prefer not to work. In the case of low-educated workers, they do not have enough incentive to work formally because they cannot reach a FP by the age of 60. After that, the outside option (leisure and home production) is more attractive.

These distributions show that low-educated workers work less in the formal sector. On average, by the age of 70, under this policy, low-educated workers spend about two fewer years in formal employment relative to the benchmark, an effect that is primarily explained by the right side of the distribution. Individuals with high and medium levels of education also work for fewer years in the formal sector by the age of 70 relative to the benchmark, respectively on average 4 and 3.4 years fewer. In all these cases, it is explained mainly by the fact that they prefer to retire as soon as possible. Moreover, the distribution for workers with high and medium education levels is more concentrated around the threshold of 30 years than in the benchmark.

The second policy places stricter requirements to achieve both the FP and AP. The minimum years in formal employment to achieve them are 35 and 20 instead of 30 and 10 years respectively. The first panel of Fig. 3 shows the pension eligibility for the three levels of education. In this scenario, again, the changes are principally for those with low and medium education levels; among the former, almost $6 \%$ do not even reach the AP, and only $18 \%$ achieve a FP. For individuals with medium levels of education, more workers ( $7 \%$ 


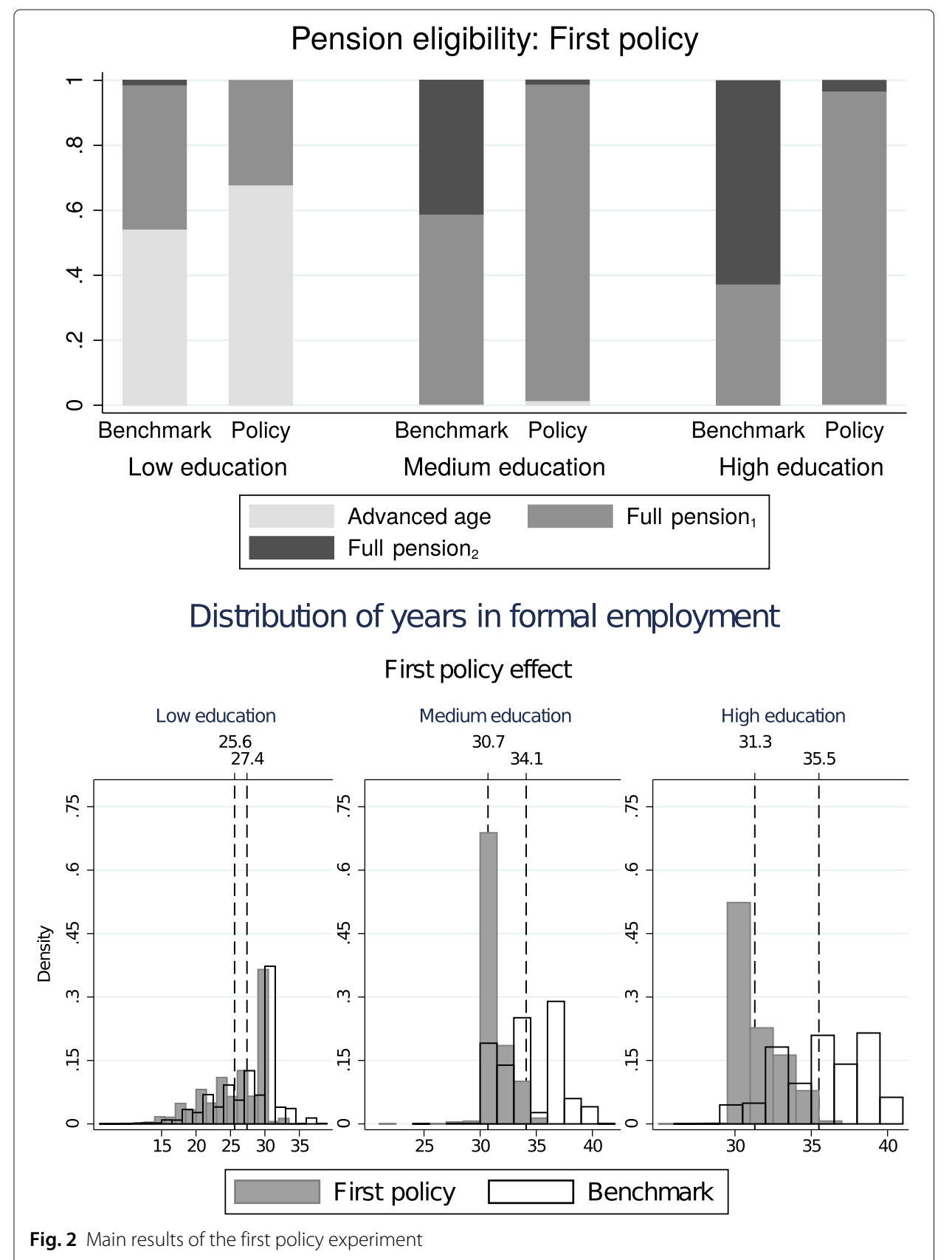

instead of $0.3 \%$ ) only obtain the AP and the first level of the FP (92\% instead of 58\%); the second and third levels were reached by about $41 \%$ in the benchmark, and this percentage is only $1 \%$ with the policy experiment. These changes are explained by the increase in formal employment among individuals over 55 years of age at all education levels. For workers with low and medium education levels, it is about $7 \%$ higher, and for the highly educated, the difference is $1.5 \%{ }^{23}$.

The years in formal employment is shown in the second panel of Fig. 3. There are changes in the distribution around the new threshold for all education levels, with the mass of the distribution going from around 30 to 35 years. The distribution of years in 


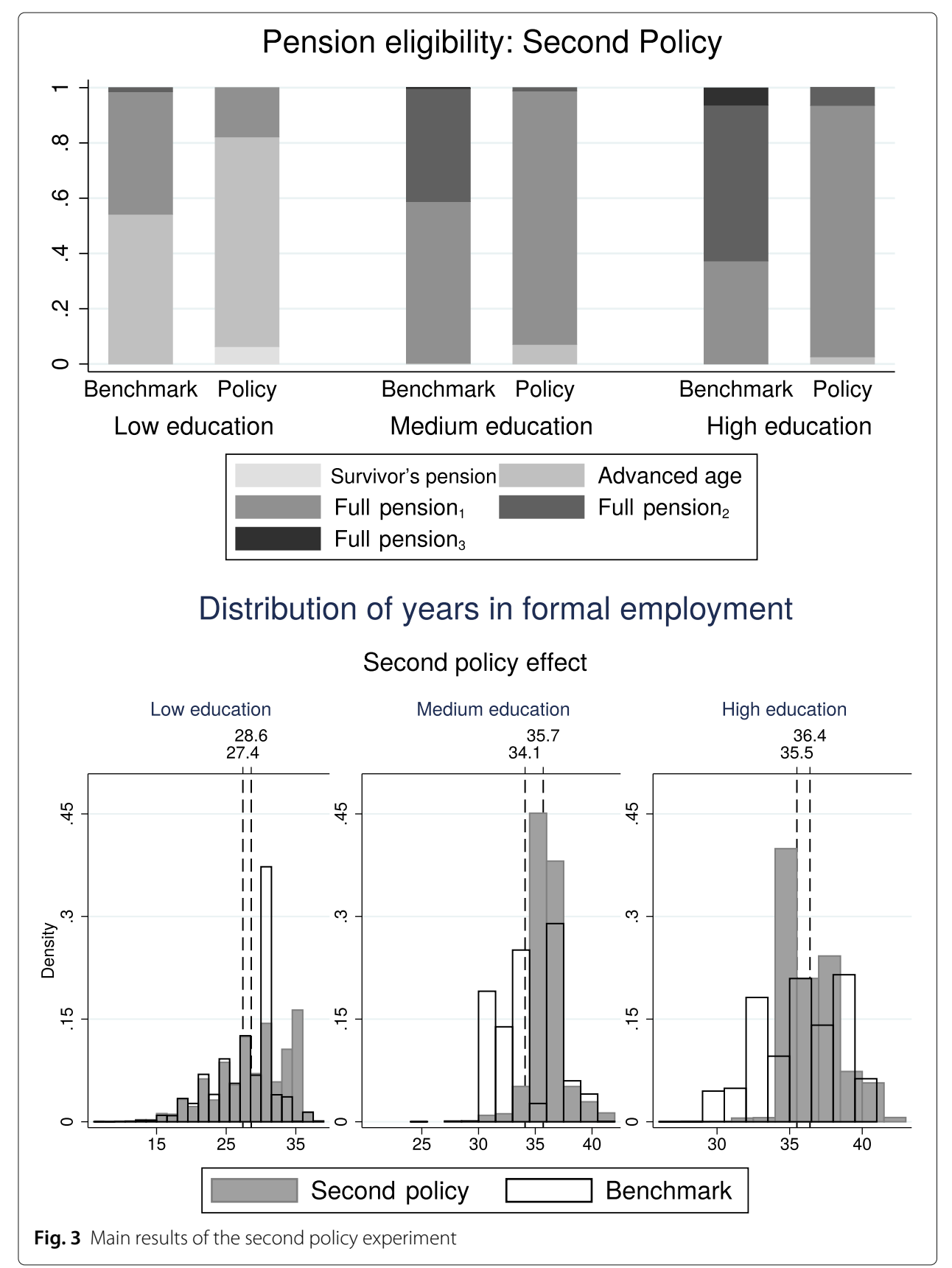

formal work is more concentrated among workers with medium and high education levels, and for the low-educated ones, it is more disperse. Additionally, the average years in formality increases for all education levels.

The third policy sets looser requirements to achieve a FP, at only 25 years in formal employment for the first level ( 30 and 35 years for the second and third level). The second panel of Fig. 4 shows the percentage of individuals who are entitled to a pension; the percentage of workers qualifying for an AP is half of the benchmark (23\% as compared to $54 \%$ ) even if they work fewer years overall in the formal sector, because this decrease occurs at the end of their career, when they reach the new minimum threshold and retire. 


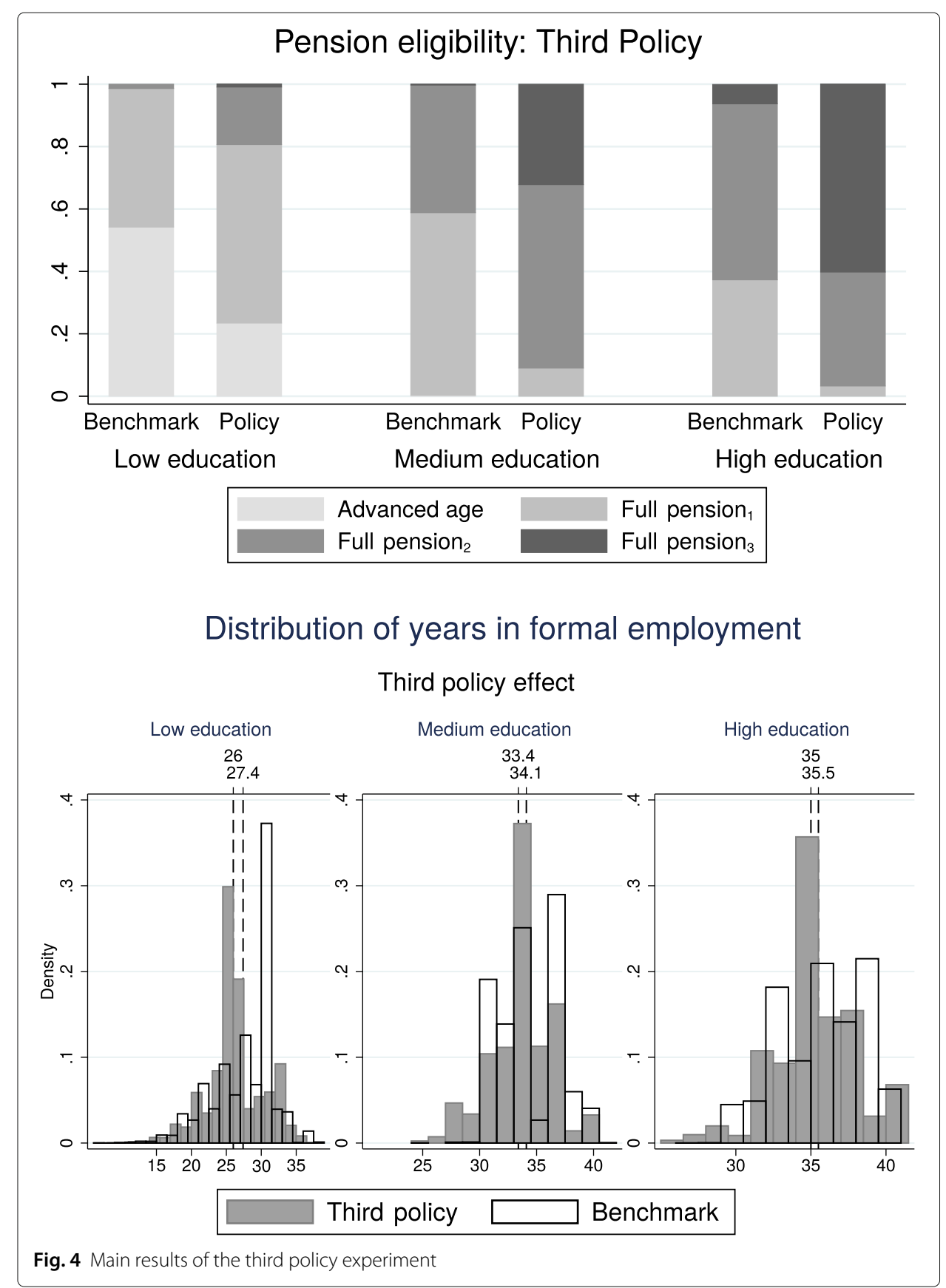

This policy decreases the years in formal employment for all education levels, especially towards the end of careers (over the age of 45$)^{24}$.

There are shifts to the left in the distribution as shown in the second panel of Fig. 4, redistributing the mass of the distribution around the new thresholds, at 25 or 35 years depending on the level of education. In this case, the distribution at all education levels is more disperse than in the benchmark.

Finally, the fourth policy is designed to put stricter requirements on the minimum age to retire: 67 and 72 instead of 65 and 70 for the FP and AP respectively. This policy experiment is considered in order to obtain more resources to cover deficits ${ }^{25}$. Workers at all 
education levels work more years in formal employment than in the benchmark after the age of 45 , and on average, they work between 1.5 and 2 years more in the formal sector ${ }^{26}$.

Pension eligibility is shown in the first panel of Fig. 5: at all education levels more workers are eligible for better pensions because they work more years in formal employment. However, $42 \%$ of low-educated workers only achieve an AP. Workers with medium and high levels of education achieve a higher level of FP, receiving a better payment.

The distribution of the total years in formal employment is shown in the second panel of Fig. 5. There is a shift to the right across the entire distribution for all education levels.

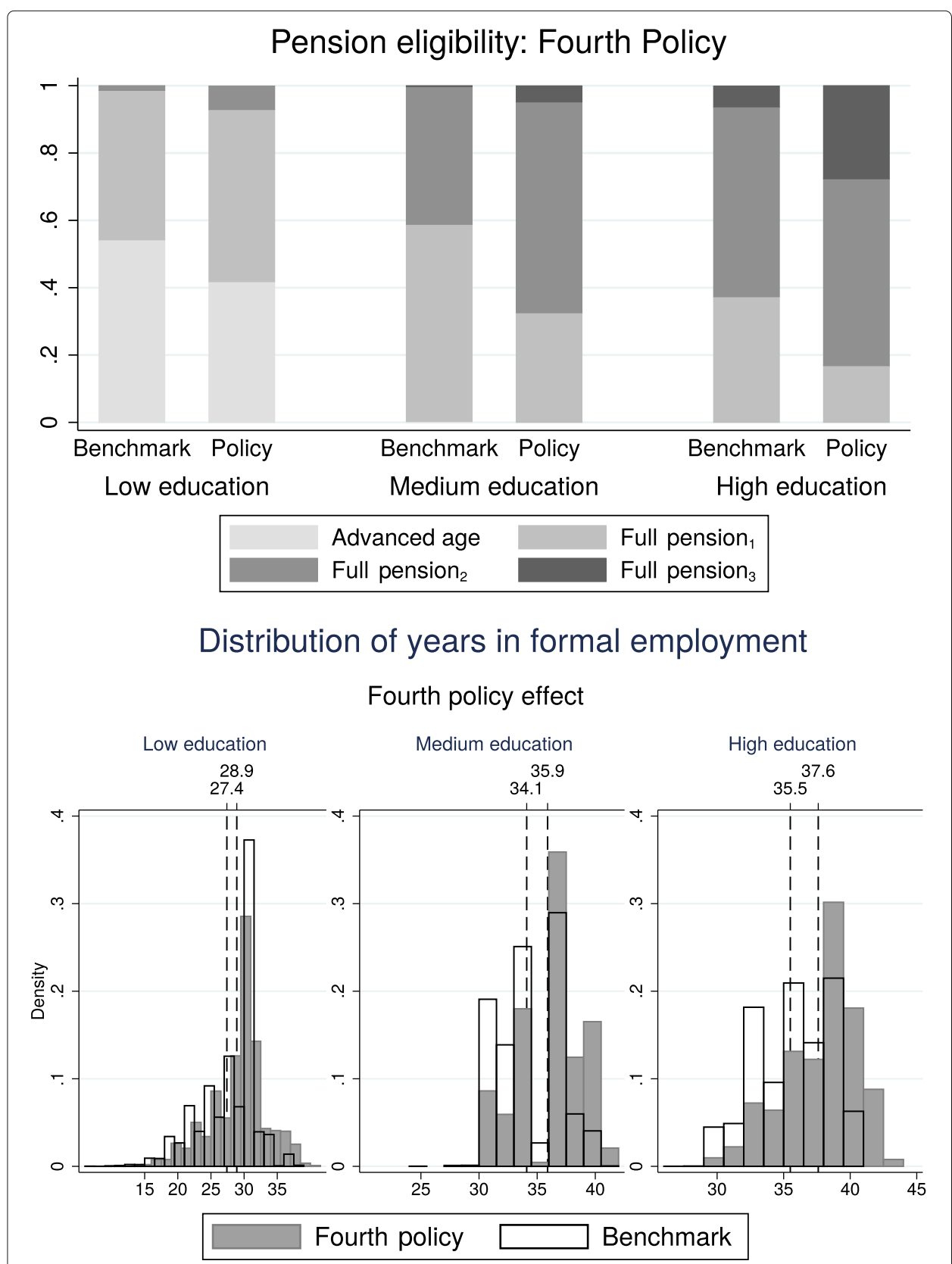

Fig. 5 Main results of the fourth policy experiment 
Finally, the dispersion of the distribution is greater than in the benchmark for all workers, but in particular for the low-educated ones.

The policy experiments have an impact, especially after the age of 55, at which age workers decide either to work additional years in formal employment or not. This decision has an impact on the number of years working in the formal sector and its distribution (chiefly around the thresholds) and more importantly on pension eligibility. The benchmark situation of most workers qualifying for a pension is analyzed with these last results, where moderate changes in the strictness of the requirements have a large impact on numbers eligible.

Finally, to compute welfare changes of these policies, I analyze how much the workers' value function changes when they start their working life ${ }^{27}$. These functions will be affected by the number of years they work in the formal or informal sector and the type of pension that they ultimately obtain. As shown in Table 8, policies have a positive impact on welfare when the requirements are stricter for low-educated individuals: despite qualifying for lower pension thresholds, they work for more years and more so in formal work. Looser requirements reduce welfare, mainly among the medium- and higheducated workers where some individuals may be presenting a certain myopia in opting for the pension as early as possible.

All of these reforms imply changes in trajectories and pension entitlements. Loweducated workers tend to have more difficulties qualifying for a pension, but incentives are insufficient to solve the situation. Even if stricter requirements incentivize formal work, there will be market segmentation barriers which prevent them from accessing better pensions.

\section{Conclusions}

In this paper, I develop a theoretical model where workers choose between working in the formal or the informal sector. These choices depend on the wages that are paid in each sector (by education and experience) and the benefits that the workers can enjoy in retirement age. The model estimation replicates the data about the existence of a large share of informal salaried workers, especially among low-educated workers.

The Argentinean pension system is considered to be strict in terms of the requirements to be eligible for coverage at retirement age, which is a more significant problem for low-educated workers. However, the requirements to qualify for an AP are not so strict for a salaried worker (only 10 years), and both in my estimations and in the literature, essentially all workers are eligible for at least this pension.

The model estimation captures the informality at all the education levels and also the transitions between formality, informality, and unemployment. Pension eligibility is in

Table 8 Welfare consequences

\begin{tabular}{lllll}
\hline & Low education (\%) & Medium education (\%) & High education (\%) & General (\%) \\
\hline First policy & 8.9 & -0.4 & -0.6 & 4.8 \\
Second policy & 7.8 & -1.1 & -1.8 & 3.9 \\
Third policy & -0.5 & -2.2 & -3.2 & -1.3 \\
Fourth policy & 8.0 & -1.1 & -1.5 & 4.0 \\
\hline
\end{tabular}

General is the weighted average with the weights $(0.477,0.365$ and 0.158 respectively) 
line with other estimates in the literature, showing that among salaried workers the main problem lies among the low-educated ones.

The policy experiments show that workers decide to work less in the formal sector when the compulsory career is shorter and replacement rates are lower (PAYG scheme), even if they ultimately obtain a lower pension income. When requirements become stricter, they work more in formal employment, especially among those workers who are closer to the new thresholds. It is remarkable that when the requirement for the first level of the FP is less strict, they work less in formal employment which rules out a higher pension, even among those who are at the top of the distribution. The main changes in behavior occur in the last part of careers, above the age of 45 .

The main difficulties obtaining pension entitlements are concentrated among loweducated workers. This paper shows that looser requirements can improve access to pension benefits, but this has little impact on individual welfare. Overall incentives towards formalization in the labor market appear insufficient to ensure pension rights for almost one quarter of the salaried population.

\section{Endnotes}

${ }^{1}$ Note that the practices are not viewed as a crime in many countries by either the citizens or the government. As mentioned by Posner (1997), some laws perceived as social norms are difficult to enforce because the legislation is not well-specified for enforcement purposes.

${ }^{2}$ Covered workers are those who have a written contract. This definition tries to capture some measures of informality.

${ }^{3}$ I use the rotating panel Permanent Household Survey for the 1995-2008 period; more details in the Appendix.

${ }^{4}$ All the regressions includes year effects to capture the countercyclical characteristic of the informality of the period (Loayza et al. 2009).

${ }^{5}$ Low, medium, and high education represent $47.7,36.5$, and $15.8 \%$ of the total of salaried workers.

${ }^{6}$ Medium education means completed high school, and high education means completed college.

${ }^{7}$ This prediction considers the whole 1995-2008 period.

${ }^{8}$ Among Latin American countries, Argentina (1994), Bolivia (1997), Chile (1981), Colombia (1993), Costa Rica (1995), Dominican Republic (2003), El Salvador (1998), Mexico (1997), Panama (2008), Peru (1993), and Uruguay (1996).

${ }^{9}$ There were 12.8 working age people (15-64) per each old individual (65 or more) in 1975 in South America; this number fell to 11.4 in 2000, and the estimation for the next few years suggests a significant fall, with 6.7 working age people for 2025 and 3.7 for 2050 (United Nations 1999). This pattern is caused not only by the rise in life expectancy but also by the fall in birth rates (United Nations 2003).

${ }^{10}$ As is shown in Appendix: Figure 6, Argentina was already at an advanced stage of demographic transition even in the middle of the last century, and in the projection for 2025, it is much closer to high-income countries. Moreover, nowadays, the birth rate is 16.7 births per 1000 people and life expectancy is 76.2.

${ }^{11}$ The details can be seen in (Arza 2009). 
${ }^{12}$ The variable set of the equation of the model is presented in the "Mathematical model" section in the Appendix.

${ }^{13}$ See the "Data" section in the Appendix.

${ }^{14}$ Employers in the model do not distinguish formal from informal experience; both are computed as the same.

${ }^{15}$ I match 69 moments to estimate 24 parameters.

${ }^{16}$ For instance, (Joubert 2015) find 1.55 for Chile.

${ }^{17}$ It is presented in Appendix: Table 15.

${ }^{18}$ As is shown in Appendix: Table 16.

${ }^{19}$ At age 65 , the only pension that they can obtain is the FP.

${ }^{20}$ In the benchmark calibration, I consider the replacement rate in the case of an individual capitalization scheme; here, I consider the replacement rate of PAYG.

${ }^{21}$ The rates of replacement are now 0.8 and 0.7 in the FP instead of 0.96 and 0.81 ; the $\mathrm{AP}$ is $70 \%$ of the latter one.

${ }^{22}$ The formality path by education level is shown in Appendix: Table 17.

${ }^{23}$ More details are shown in Appendix: Table 18.

${ }^{24}$ More details are shown in Appendix: Table 19.

${ }^{25}$ Note that if most low-educated workers continue working after the age of 65 , then this requirement will not affect them. The budget could be affected if more workers have access to a FP with higher replacement rates, but those parameters do not deeply affect workers' behavior.

${ }^{26}$ More details are shown in Appendix: Table 20.

${ }^{27}$ Following (Auberbach and Kotlikoff 1987) and (Fehr et al. 2012).

${ }^{28}$ Urban populations accounts for $90 \%$ of the total population of Argentina, so the survey gives a good representation of the country.

\section{Appendix}

\section{Data}

I use the Permanent Household Survey (EPH in Spanish) carried out by the National Institute of Statistics and Census (INDEC in Spanish) for the 1995 to 2008 period. The sample is restricted to urban regions, covering 28 large urban centers where $70 \%$ of the urban population of Argentina live ${ }^{28}$.

Between 1995 and 2002, the survey was biannual (first and third quarter), and in 2003, it became quarterly. In the first period, the panel is rotating, losing $25 \%$ of the cases every 6 months. In the second period, the rotation has the following characteristics: (i) two consecutive quarters share $50 \%$ of the cases, (ii) two quarters with one quarter in the middle do not have any cases in common, and (iii) two quarters with two quarters in the middle share $25 \%$ of cases. Any quarter shares $25 \%$ of the cases with the same one in consecutive years. In the whole period, it is possible to follow some individuals for one and a half years.

This survey has a socioeconomic purpose, and it is crucial in identifying workers in different sectors of the economy. The identification of formal workers is directly assessed by asking if the employer pays the social contribution to have the right to access a pension payment in retirement. Unfortunately, the questionnaire does not ask anything about the contribution of the self-employed. This is the main shortcoming of this survey, so my research only analyzes the dynamic among salaried workers. This feature allows me 


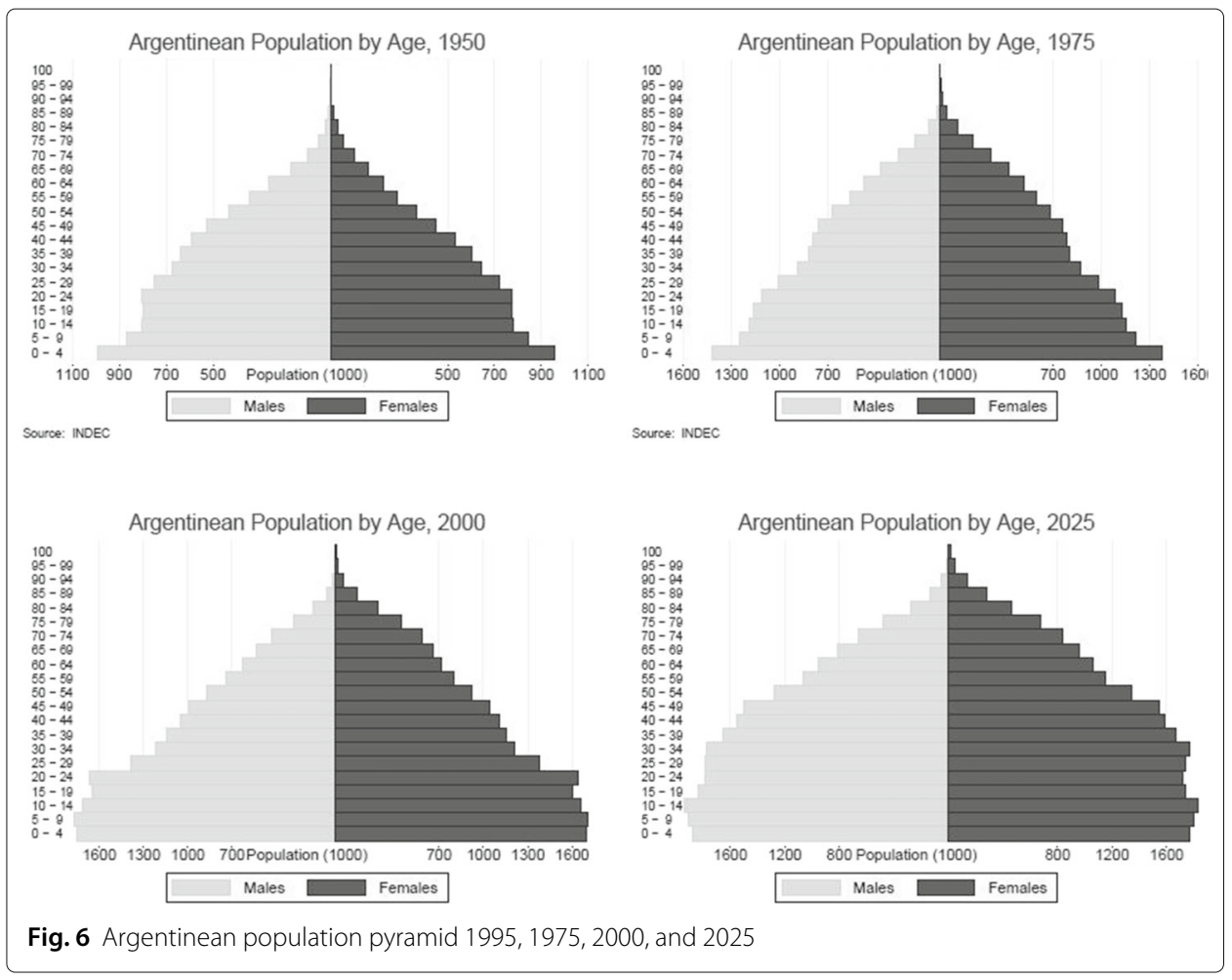

to analyze the transitions between formal, informal, and unemployed situations without taking into consideration self-employment as a possible escape from unemployment.

\section{Mathematical model}

$$
\begin{aligned}
& \Omega(t)=\left[a, S, X, a_{F}, \mathbf{I}_{k}^{t-1}, \epsilon(a)^{j}\right] \\
& k=\{\text { Formal (F), Informal (I), Unemployed (U) }\} \\
& j=\{\text { Formal (F), Informal (I) }\} \\
& \ln \left(R^{j}(S, X)\right)=\alpha_{0}^{j}+\alpha_{1}^{j} S+\alpha_{2}^{j} X+\alpha_{3}^{j}\left(\frac{X}{10}\right)^{2}+\epsilon(a)^{j}+B_{1}(S) \\
& j=\{\text { Formal (F), Informal (I) }\} \epsilon^{j} \sim N(0, \Sigma) \quad \Sigma=\left(\begin{array}{cc}
\sigma^{f} & 0 \\
0 & \sigma^{i}
\end{array}\right)
\end{aligned}
$$

Table 9 Informality (as the lack of pension eligibility) among salaried workers in Latin America (2009)

\begin{tabular}{llll}
\hline Country & Mean & Male & Female \\
\hline Uruguay & 20.3 & 13.0 & 17.7 \\
Chile & 23.6 & 16.6 & 24.6 \\
Argentina & 36.1 & 27.0 & 35.5 \\
Colombia & 42.7 & 36.6 & 38.4 \\
Ecuador & 52.0 & 48.2 & 45.3 \\
Mexico & 55.5 & 50.5 & 47.0 \\
\hline Source: CELADES & & &
\end{tabular}


Table 10 Informality rates among salaried workers by schooling level in 2009

\begin{tabular}{llll}
\hline Country & Low education & Medium education & High education \\
\hline Uruguay & 27.0 & 11.0 & 3.3 \\
Chile & 31.8 & 18.6 & 12.6 \\
Argentina & 51.6 & 32.0 & 14.4 \\
Colombia & 62.9 & 30.1 & 8.2 \\
Ecuador & 74.9 & 47.5 & 21.6 \\
Mexico & 73.9 & 43.6 & 24.6 \\
\hline
\end{tabular}

Source: CELADES

Table 11 Probabilities of being in each sector (men only) based on the multinomial model

\begin{tabular}{|c|c|c|c|}
\hline \multicolumn{4}{|c|}{ Age group: 23-28 years old } \\
\hline Unemployed & Unemployed $(-1)$ & Formal $(-1)$ & Informal $(-1)$ \\
\hline Low education & 0.3805 & 0.0597 & 0.1079 \\
\hline Medium education & 0.3741 & 0.0371 & 0.1094 \\
\hline High education & 0.3889 & 0.0329 & 0.1416 \\
\hline Formal & Unemployed (-1) & Formal $(-1)$ & Informal $(-1)$ \\
\hline Low education & 0.1531 & 0.7707 & 0.1402 \\
\hline Medium education & 0.2291 & 0.8636 & 0.2276 \\
\hline High education & 0.3220 & 0.9086 & 0.3241 \\
\hline Informal & Unemployed $(-1)$ & Formal $(-1)$ & Informal $(-1)$ \\
\hline Low education & 0.4664 & 0.1695 & 0.7519 \\
\hline Medium education & 0.3969 & 0.0993 & 0.6630 \\
\hline High education & 0.2891 & 0.0584 & 0.534 \\
\hline \multicolumn{4}{|c|}{ Age group: 29-34 years old } \\
\hline Unemployed & Unemployed (-1) & Formal $(-1)$ & Informal $(-1)$ \\
\hline Low education & 0.3726 & 0.0413 & 0.0941 \\
\hline Medium education & 0.3533 & 0.0247 & 0.1021 \\
\hline High education & 0.3255 & 0.0151 & 0.1010 \\
\hline Formal & Unemployed $(-1)$ & Formal $(-1)$ & Informal $(-1)$ \\
\hline Low education & 0.1781 & 0.8215 & 0.1733 \\
\hline Medium education & 0.2723 & 0.8992 & 0.2671 \\
\hline High education & 0.3902 & 0.9435 & 0.4046 \\
\hline Informal & Unemployed $(-1)$ & Formal $(-1)$ & Informal $(-1)$ \\
\hline Low education & 0.4493 & 0.1372 & 0.7326 \\
\hline Medium education & 0.3744 & 0.0762 & 0.6308 \\
\hline High education & 0.2843 & 0.0415 & 0.4944 \\
\hline \multicolumn{4}{|c|}{ Age group: $35-44$ years old } \\
\hline Unemployed & Unemployed $(-1)$ & Formal $(-1)$ & Informal $(-1)$ \\
\hline Low education & 0.3736 & 0.0356 & 0.1039 \\
\hline Medium education & 0.3480 & 0.0199 & 0.1043 \\
\hline High education & 0.2972 & 0.0104 & 0.0977 \\
\hline Formal & Unemployed $(-1)$ & Formal $(-1)$ & Informal $(-1)$ \\
\hline Low education & 0.2003 & 0.8471 & 0.1888 \\
\hline Medium education & 0.3055 & 0.9171 & 0.3058 \\
\hline High education & 0.4405 & 0.9560 & 0.4438 \\
\hline Informal & Unemployed $(-1)$ & Formal $(-1)$ & Informal $(-1)$ \\
\hline Low education & 0.4262 & 0.1173 & 0.7073 \\
\hline Medium education & 0.3466 & 0.0630 & 0.5899 \\
\hline High education & 0.2623 & 0.0336 & 0.4585 \\
\hline
\end{tabular}


Table 12 Probabilities of being in each sector (men only) based on the multinomial model

\begin{tabular}{llll}
\hline Age group: 45-54 years old & & & \\
Unemployed & Unemployed $(-1)$ & Formal $(-1)$ & Informal (-1) \\
Low education & 0.3829 & 0.0330 & 0.1143 \\
Medium education & 0.3352 & 0.0179 & 0.1152 \\
High education & 0.2999 & 0.0094 & 0.0936 \\
Formal & Unemployed $(-1)$ & Formal $(-1)$ & Informal (-1) \\
Low education & 0.2220 & 0.8654 & 0.2072 \\
Medium education & 0.3450 & 0.9275 & 0.3289 \\
High education & 0.4725 & 0.9616 & 0.4876 \\
Informal & Unemployed $(-1)$ & Formal $(-1)$ & Informal (-1) \\
Low education & 0.3951 & 0.1016 & 0.6786 \\
Medium education & 0.3198 & 0.0546 & 0.5559 \\
High education & 0.2277 & 0.0291 & 0.4188 \\
Age group: $55-65$ years old & & & \\
Unemployed & Unemployed $(-1)$ & Formal $(-1)$ & Informal $(-1)$ \\
Low education & 0.4235 & 0.0379 & 0.1351 \\
Medium education & 0.3568 & 0.0209 & 0.1395 \\
High education & 0.2624 & 0.0092 & 0.0864 \\
Formal & Unemployed $(-1)$ & Formal $(-1)$ & Informal $(-1)$ \\
Low education & 0.2245 & 0.8688 & 0.2226 \\
Medium education & 0.3605 & 0.9290 & 0.3437 \\
High education & 0.5372 & 0.9654 & 0.5351 \\
Informal & Unemployed $(-1)$ & Formal $(-1)$ & Informal $(-1)$ \\
Low education & 0.3520 & 0.0933 & 0.6423 \\
Medium education & 0.2828 & 0.0501 & 0.5168 \\
High education & 0.2003 & 0.0253 & \\
\hline
\end{tabular}

Table 13 Coverage of the pension system (men only)

\begin{tabular}{llll}
\hline Coverage of the pension system & $65-69$ & $70-74$ & $75+$ \\
\hline Contributive & 64.18 & 81.8 & 84.52 \\
Full pension & 60.06 & 75.99 & 75.37 \\
Advanced age & 3.31 & 4.95 & 8.16 \\
Non-contributory pension & 1.31 & 2.35 & 3.87 \\
\hline Source: (Arenas de Mesa et al. 2001) & & &
\end{tabular}

Table 14 Moment matching: formal, informal, and unemployed workers

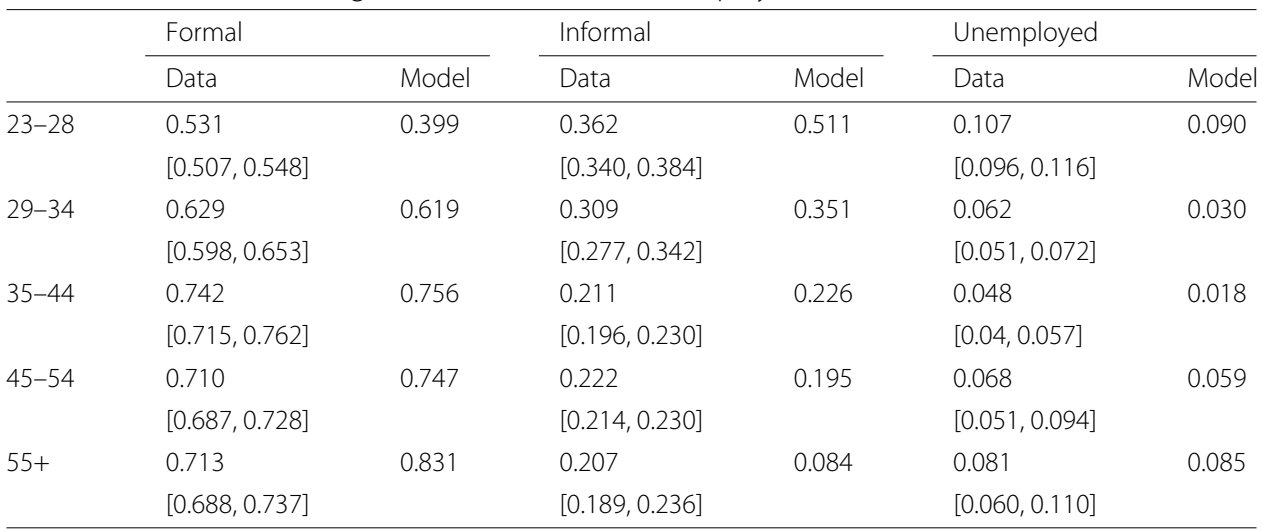

The interval is estimated by performing bootstraps and considering the middle $90 \%$ 
Table 15 Moment matching: unemployed workers

\begin{tabular}{|c|c|c|c|c|c|c|}
\hline & \multicolumn{2}{|l|}{ Low education } & \multicolumn{2}{|c|}{ Medium education } & \multicolumn{2}{|l|}{ High education } \\
\hline & Data & Model & Data & Model & Data & Mode \\
\hline \multirow[t]{2}{*}{$23-28$} & 0.1462 & 0.0862 & 0.0830 & 0.1039 & 0.0808 & 0.0661 \\
\hline & {$[0.1298,0.1703]$} & & {$[0.0694,0.0966]$} & & {$[0.0464,0.1147]$} & \\
\hline \multirow{2}{*}{ 29-34 } & 0.0845 & 0.0362 & 0.0527 & 0.0326 & 0.0172 & 0.0056 \\
\hline & {$[0.0710,0.0968]$} & & {$[0.0384,0.0675]$} & & {$[0.0090,0.0429]$} & \\
\hline \multirow[t]{2}{*}{$35-44$} & 0.0729 & 0.0342 & 0.0311 & 0.0032 & 0.0126 & 0.0034 \\
\hline & {$[0.0618,0.0861]$} & & {$[0.0232,0.0458]$} & & {$[0.0076,0.0222]$} & \\
\hline \multirow[t]{2}{*}{$45-54$} & 0.1053 & 0.1091 & 0.0220 & 0.0031 & 0.0161 & 0.0355 \\
\hline & {$[0.0696,0.1551]$} & & {$[0.0152,0.0354]$} & & {$[0.0108,0.0227]$} & \\
\hline \multirow[t]{2}{*}{$55+$} & 0.0862 & 0.0970 & 0.1044 & 0.0925 & 0.0096 & 0.0307 \\
\hline & {$[0.0624,0.1122]$} & & {$[0.0514,0.1687]$} & & {$[0.0047,0.0174]$} & \\
\hline
\end{tabular}

The interval is estimated based on the multinomial model, performing bootstraps and considering the middle 90\%

Table 16 Moment matching: transitions

\begin{tabular}{|c|c|c|c|c|c|c|}
\hline & \multicolumn{2}{|l|}{ Unemployment } & \multicolumn{2}{|l|}{ Formal } & \multicolumn{2}{|l|}{ Informal } \\
\hline & Data & Model & Data & Model & Data & Model \\
\hline \multirow[t]{2}{*}{ Unemployed $(-1)$} & 0.4414 & 0.3228 & 0.1928 & 0.2593 & 0.3658 & 0.4181 \\
\hline & {$[0.3668,0.5152]$} & & {$[0.1501,0.2268]$} & & {$[0.3141,0.4193]$} & \\
\hline \multirow{2}{*}{ Formal $(-1)$} & 0.0295 & 0.0267 & 0.8824 & 0.8347 & 0.0881 & 0.1388 \\
\hline & {$[0.0238,0.0425]$} & & {$[0.8751,0.8907]$} & & {$[0.0761,0.0974]$} & \\
\hline \multirow[t]{2}{*}{ Informal (-1) } & 0.0743 & 0.1234 & 0.2393 & 0.4755 & 0.6864 & 0.4013 \\
\hline & {$[0.0593,0.1034]$} & & {$[0.2142,0.2673]$} & & {$[0.6719,0.7068]$} & \\
\hline
\end{tabular}

The interval is estimated based on the multinomial model, performing bootstraps and considering the middle $90 \%$

Table 17 Formality path with the first policy experiment: replacement rates and retirement age at 60

\begin{tabular}{|c|c|c|c|c|c|c|c|c|}
\hline & \multicolumn{2}{|l|}{ General } & \multicolumn{2}{|c|}{ Low education } & \multicolumn{2}{|c|}{ Medium education } & \multicolumn{2}{|c|}{ High education } \\
\hline & Benchmark & Policy & Benchmark & Policy & Benchmark & Policy & Benchmark & Policy \\
\hline $23-28$ & 0.399 & 0.404 & 0.265 & 0.274 & 0.481 & 0.484 & 0.615 & 0.618 \\
\hline $29-34$ & 0.619 & 0.616 & 0.512 & 0.503 & 0.692 & 0.694 & 0.778 & 0.777 \\
\hline $35-44$ & 0.756 & 0.745 & 0.651 & 0.649 & 0.852 & 0.851 & 0.854 & 0.853 \\
\hline $45-54$ & 0.747 & 0.755 & 0.544 & 0.556 & 0.943 & 0.944 & 0.904 & 0.918 \\
\hline $55+$ & 0.831 & 0.677 & 0.764 & 0.564 & 0.875 & 0.785 & 0.933 & 0.770 \\
\hline
\end{tabular}

Table 18 Formality path with the second policy experiment: 35 years of formal work as FP requirement and 20 years of formality as Advanced age pension requirement

\begin{tabular}{|c|c|c|c|c|c|c|c|c|}
\hline & \multicolumn{2}{|l|}{ General } & \multicolumn{2}{|c|}{ Low education } & \multicolumn{2}{|c|}{ Medium education } & \multicolumn{2}{|c|}{ High education } \\
\hline & Benchmark & Policy & Benchmark & Policy & Benchmark & Policy & Benchmark & Policy \\
\hline $23-28$ & 0.399 & 0.398 & 0.265 & 0.264 & 0.481 & 0.480 & 0.615 & 0.612 \\
\hline $29-34$ & 0.619 & 0.622 & 0.512 & 0.513 & 0.692 & 0.697 & 0.778 & 0.780 \\
\hline $35-44$ & 0.756 & 0.746 & 0.651 & 0.628 & 0.852 & 0.851 & 0.854 & 0.857 \\
\hline $45-54$ & 0.747 & 0.757 & 0.544 & 0.550 & 0.943 & 0.955 & 0.904 & 0.924 \\
\hline $55+$ & 0.831 & 0.891 & 0.764 & 0.838 & 0.875 & 0.937 & 0.933 & 0.949 \\
\hline
\end{tabular}

Table 19 Formality path with the third policy experiment: 25 years of formal work as FP requirement

\begin{tabular}{|c|c|c|c|c|c|c|c|c|}
\hline & \multicolumn{2}{|l|}{ General } & \multicolumn{2}{|c|}{ Low education } & \multicolumn{2}{|c|}{ Medium education } & \multicolumn{2}{|c|}{ High education } \\
\hline & Benchmark & Policy & Benchmark & Policy & Benchmark & Policy & Benchmark & Policy \\
\hline $23-28$ & 0.399 & 0.398 & 0.265 & 0.264 & 0.481 & 0.484 & 0.615 & 0.619 \\
\hline $29-34$ & 0.619 & 0.620 & 0.512 & 0.513 & 0.692 & 0.694 & 0.778 & 0.780 \\
\hline $35-44$ & 0.756 & 0.758 & 0.651 & 0.628 & 0.852 & 0.853 & 0.854 & 0.854 \\
\hline $45-54$ & 0.747 & 0.720 & 0.544 & 0.544 & 0.943 & 0.894 & 0.904 & 0.848 \\
\hline $55+$ & 0.831 & 0.807 & 0.764 & 0.743 & 0.875 & 0.839 & 0.933 & 0.922 \\
\hline
\end{tabular}


Table 20 Formality path with the fourth policy experiment: age of 67 as FP requirement

\begin{tabular}{|c|c|c|c|c|c|c|c|c|}
\hline & \multicolumn{2}{|l|}{ General } & \multicolumn{2}{|c|}{ Low education } & \multicolumn{2}{|c|}{ Medium education } & \multicolumn{2}{|c|}{ High education } \\
\hline & Benchmark & Policy & Benchmark & Policy & Benchmark & Policy & Benchmark & Policy \\
\hline $23-28$ & 0.399 & 0.402 & 0.265 & 0.271 & 0.481 & 0.484 & 0.615 & 0.617 \\
\hline $29-34$ & 0.619 & 0.619 & 0.512 & 0.509 & 0.692 & 0.693 & 0.778 & 0.776 \\
\hline $35-44$ & 0.756 & 0.753 & 0.651 & 0.652 & 0.852 & 0.850 & 0.854 & 0.852 \\
\hline $45-54$ & 0.747 & 0.755 & 0.544 & 0.550 & 0.943 & 0.948 & 0.904 & 0.928 \\
\hline $55+$ & 0.831 & 0.868 & 0.764 & 0.822 & 0.875 & 0.894 & 0.933 & 0.948 \\
\hline
\end{tabular}

$$
\begin{aligned}
& R^{U}(a, X, S)= \begin{cases}b_{2} \mathbf{E}\left[R^{F}(a-1)\right]+B_{2}(X, S) \text { if } \mathbf{I}_{F}^{-1}=1 \text { with } 0 \leq b_{2} \leq 1 \\
B_{2}(X, S) & \text { otherwise }\end{cases} \\
& B_{2}(X, S)=b_{21}(S)\left(b_{22}+\frac{b_{23}(S)}{X}\right) \\
& V(\Omega(t))=\max \left\{V^{F}, V^{I}, V^{U}\right\} \\
& V^{j}(\Omega(a))= U\left(R^{j}(a)-\mathbb{C}^{F k}(a, S) \mathbf{I}^{-k}\right) \\
&+\beta\left[\lambda_{j}(S) \mathbf{E}_{\Omega(a+1) / \Omega(a)} V^{U}(\Omega(a+1))\right. \\
&\left.+\left(1-\lambda_{j}(S)\right) \mathbf{E}_{\Omega(a+1) / \Omega(a)} \max \left\{V^{I}(\Omega(a+1)), V^{F}(\Omega(a+1))\right\}\right] \\
& j=\{\text { Formal (F), Informal (I) }\}
\end{aligned}
$$

$$
\begin{gathered}
\mathbb{C}^{F j}\left(a, S, \mathbf{I}^{-k}\right)=\left\{\begin{array}{lll}
(\Pi-a) \phi_{11}(S) & \text { if } & \mathbf{I}^{-k}=\text { informal } \\
(\Pi-a) \phi_{12}(S) & \text { if } & \mathbf{I}^{-k}=\text { unemployed } \\
0 & \text { if } & \mathbf{I}^{-k}=\text { formal }
\end{array}\right. \\
k=\{\text { Formal (F), Informal (I), Unemployed (U) }\}
\end{gathered}
$$

Table 21 Transitions with the policy experiments

\begin{tabular}{llllll}
\hline & \multicolumn{3}{l}{ Transitions } & & \\
\cline { 2 - 5 } & Benchmark & 1st policy & 2nd policy & 3rd policy & 4th policy \\
\hline Informal-formal & 0.476 & 0.485 & 0.484 & 0.465 & 0.474 \\
Informal-unemployed & 0.123 & 0.113 & 0.100 & 0.138 & 0.122 \\
Informal-informal & 0.401 & 0.402 & 0.416 & 0.397 & 0.404 \\
Formal-formal & 0.835 & 0.795 & 0.85 & 0.825 & 0.853 \\
Formal-unemployed & 0.027 & 0.036 & 0.014 & 0.033 & 0.019 \\
Formal-informal & 0.139 & 0.166 & 0.136 & 0.142 & 0.129 \\
Unemployed-formal & 0.259 & 0.347 & 0.224 & 0.349 & 0.234 \\
Unemployed-unemployed & 0.323 & 0.218 & 0.223 & 0.292 & 0.292 \\
Unemployed-informal & 0.418 & 0.435 & 0.553 & 0.359 & 0.475 \\
\hline
\end{tabular}




$$
\begin{aligned}
V^{U}(\Omega(a))= & U\left(R^{U}(a)\right) \\
& +\beta\left[\left(1-\phi_{F}(S)-\phi_{I}(S)\right) \mathbf{E}_{\Omega(a+1) / \Omega(a)} V^{U}(\Omega(a+1))\right. \\
& +\phi_{F}(S) \mathbf{E}_{\Omega(a+1) / \Omega(a)} \max \left\{V^{U}(\Omega(a+1)), V^{F}(\Omega(a+1))\right\} \\
& \left.+\phi_{I}(E) \mathbf{E}_{\Omega(a+1) / \Omega(a)} \max \left\{V^{U}(\Omega(a+1)), V^{I}(\Omega(a+1))\right\}\right] \\
U\left(R^{k}(a)\right)= & \frac{1}{1-\gamma} R^{k}(a)^{\frac{1}{1-\gamma}} \\
V^{P}(\Omega(a))= & U\left(r_{F} R^{k}(a)+B_{3}(S)\right)+\beta \mathbf{E}_{\Omega(a+1) / \Omega(a)} V(\Omega(a+1)) \\
V(\Omega(a))= & \max \left\{V^{U}(\Omega(a)), V^{I}(\Omega(a)), V^{F}(\Omega(a)) V^{P}(\Omega(a))\right\}
\end{aligned}
$$$$
\mathbf{I}_{a_{F} \geq 30}= \begin{cases}1 & \text { if the individual has worked in the formal sector for } 30 \text { years } \\ 0 & \text { otherwise }\end{cases}
$$$$
V(\Omega(a))=U\left(r_{F} R^{k}(a)+B_{3}(S)\right) \mathbf{I}_{a_{F} \geq 30}+U\left(r_{A} R^{k}(a)+B_{3}(S)\right) \mathbf{I}_{30>a_{F} \geq 10}
$$$$
+U\left(b_{3}+B_{3}(S)\right) \mathbf{I}_{a_{F}<10}+\beta \mathbf{E}_{\Omega(a+1) / \Omega(a)} V(\Omega(a+1))
$$

$$
B_{3}(S)=b_{31}(S)
$$

$\mathbf{I}_{30>a_{F} \geq 10}= \begin{cases}1 & \begin{array}{l}\text { if they have worked in the formal sector for } 10 \text { years or more } \\ \text { and less than } 30 \\ 0\end{array} \\ \text { otherwise }\end{cases}$

\section{Acknowledgements}

I thank Russell Cooper, Andrea Ichino, Jérôme Adda, Marco Manacorda, Giovanni Pica, and Roxana Maurizio. I also thank all the participants of the January forum at the European University Institute and the XVIth Applied Economics Meeting 2013 in Granada, Spain.

I would like to thank the editor and the anonymous referee for the useful remarks.

Responsible editor: Juan Jimeno

\section{Competing interests}

The IZA Journal of Labor Policy is committed to the IZA Guiding Principles of Research Integrity. The author declares that he has observed these principles.

\section{Publisher's Note}

Springer Nature remains neutral with regard to jurisdictional claims in published maps and institutional affiliations.

Received: 2 August 2016 Accepted: 25 June 2017

Published online: 10 August 2017

\section{References}

Amaral PS, Quintin E (2006) A competitive model of the informal sector. J Monet Econ 53(7):1541-1553

Arenas de Mesa A, Bertranou F, Grushka C, Hernández Sánchez H, Pinheiro V, Rofman R (2001) Cobertura Previsional en Argentina, Brasil y Chile. Oficina Internacional del Trabajo

Arza C (2009) Back to the state: pension fund nationalization in Argentina. Discussion Paper no. 73, Centro Interdisciplinario para el Estudio de Políticas Públicas

Attanasio O, Meghir C, Otero A (2011) Formal labor market and pension wealth: evaluating the 2008 Chilean pension reform. mimeo UCL

Auberbach AJ, Kotlikoff L (1987) Dynamic fiscal policy. Cambridge University Press

Bergolo M, Cruces G (2014) Work and tax evasion incentive effects of social insurance programs: evidence from an employment-based benefit extension. J Public Econ 117:211-228 
Berstein S, Larrain G, Pino F, Moron E (2006) Chilean pension reform: coverage facts and policy alternatives. Economia 6(2):227-279

Bosch M, Guajardo J (2012) Labor market impacts of non-contributory pensions: the case of Argentina's moratorium. IDB Publications No 78158, Inter-American Development Bank

Bosch M, Manacorda M (2012) Social policies and labor market outcomes in Latin America and the Caribbean: a review of the existing evidence. CEP Occasional Papers No 32, Centre for Economic Performance, LSE

Bucheli M, Ceni R (2010) Informality sectoral selection and earnings in Uruguay. Estud Econ 25(2):281-307

Bucheli M, Forteza A, Rossi I (2010) Work histories and the access to contributory pensions: the case of Uruguay. J Pension Econ Finan 9(3):369-391

Ceni R (2013) Informality and government enforcement in Latin America. Documentos de Trabajo (working papers) No 14-21, Instituto de Economia - IECON

Fehr H, Kallweit M, Kindermann F (2012) Pension reform with variable retirement age: a simulation analysis for Germany. J Pension Econ Finan 11(03):389-417

Forteza A, Apella I, Fajnzylber E, Grushka C, Rossi I, Sanroman G (2009) Work histories and pension entitlements in Argentina, Chile and Uruguay. Social Protection Discussion Papers No 52446, World Bank

Forteza A, Ourens G (2009) How much do Latin American pension programs promise to pay back Documentos de Trabajo (working papers) No 31/09, dECON

French $E$, Jones JB (2011) The effects of health insurance and self-insurance on retirement behavior. Econometrica 79(3):693-732

Galiani S, Weinschelbaum F (2007) Modeling informality formally: households and firms. Econ Inq 50(3):821-838

Hazans M (2011) Informal workers across Europe: evidence from 30 countries. IZA Discussion Papers No 5871, Institute for the Study of Labor (IZA)

Holzmann R, Robalino D, Takayama N (2009) Closing the coverage gap: the role of social pensions and other retirement income transfers. World Bank

Joubert C (2015) Pension design with a large informal labor market: evidence from Chile. Int Econ Rev 56(2):673-694

Keane MP, Wolpin KI (1997) The career decisions of young men. J Polit Econ 105:473-522

La-Porta R, Shleifer A (2014) Informality and development. National Bureau of Economic Research, No 20205

Loayza NV, Serven L, Sugawara N (2009) Informality in Latin America and the Caribbean. Policy Research Working Paper Series No 4888, World Bank

Magnac T (1991) Segmented or competitive labor markets. Econometrica 59(1):165-87

Maloney WF (2004) Informality revisited. World Dev 32(7):1159-1178

Otero A (2013) Informality and pension incentives: a structural household life cycle model of consumption, labor supply and pension savings. Job Market Paper, University College of London

Perry GE, Maloney WF, Arias OS, Fajnzylber P, Mason AD, Saavedra-Chanduvi J (2007) Informality: exit and exclusion. World Bank

Portes A, Castells M, Benton L, Portes A (1989) The informal economy: studies in advanced and less developed countries. In: Castells M, Benton L (eds). Johns Hopkins University Press, Baltimore

Posner R (1997) Social norms and the law: an economic approach. Am Econ Rev 87(2):365-369

Pratap S, Quintin E (2006) Are labor markets segmented in developing countries? A semiparametric approach. Eur Econ Rev 50(7):1817-1841

Rofman R (2000) The pension system in Argentina six years after the reform. World Bank

Rofman R, Fajnzylber E, Herrera G (2010) Reforming the pension reforms: Argentina and Chile. Revista CEPAL

Schneider F (2012) The shadow economy and work in the shadow: what do we (not) know? IZA Discussion Papers No 6423 , Institute for the Study of Labor (IZA)

Todd P, Velez-Grajales V (2008) How pension rules affect work and contribution patterns: a behavioral model of the Chilean privatized pension system. mimeo. Retirement Research Center, University of Michigan

United Nations (1999) World population aging 1950-2050. United Nations, New York, NY. Dept. of Economic and Social Affairs

United Nations (2003) World population prospects: the 2002 revision. United Nations, New York, NY. Dept. of Economic and Social Affairs

World Bank (2010) Informality in Colombia: implications for worker welfare and firm productivity. World Bank. No. 2889

\section{Submit your manuscript to a SpringerOpen ${ }^{\circ}$ journal and benefit from:}

- Convenient online submission

- Rigorous peer review

- Open access: articles freely available online

- High visibility within the field

- Retaining the copyright to your article

Submit your next manuscript at $\boldsymbol{\triangleright}$ springeropen.com 